\title{
Effect of Cooking and Reconstitution Methods on the Loss of Bioactive Compounds in Pigmented and Unpigmented Potatoes
}

\author{
Mohammed Z. Alam¹, Gefu Wang-Pruski ${ }^{*}$, Mark Hodges ${ }^{2}$, Garry R. Hawkins ${ }^{3}$, \\ Martin Dino Kubik ${ }^{4}$, Sherry A. E. Fillmore ${ }^{2}$ \\ ${ }^{1}$ Faculty of Agriculture, Dalhousie University, Truro, Canada \\ ${ }^{2}$ Atlantic Food and Horticulture Research Centre, Agriculture and Agri-Food Canada, Kentville, Canada \\ ${ }^{3}$ McCain Foods Ltd., Florenceville-Bristol, Canada \\ ${ }^{4}$ Agriculture and Agri-Food Canada, Ottawa, Canada \\ Email: *gefu.wang-pruski@dal.ca
}

How to cite this paper: Alam, M.Z., Wang-Pruski, G., Hodges, M., Hawkins, G.R., Kubik, M.D. and Fillmore, S.A.E. (2017) Effect of Cooking and Reconstitution Methods on the Loss of Bioactive Compounds in Pigmented and Unpigmented Potatoes. Food and Nutrition Sciences, 8, 31-55.

http://dx.doi.org/10.4236/fns.2017.81003

Received: September 16, 2016

Accepted: December 9, 2016

Published: December 12, 2016

Copyright (c) 2017 by authors and Scientific Research Publishing Inc. This work is licensed under the Creative Commons Attribution International License (CC BY 4.0).

http://creativecommons.org/licenses/by/4.0/ cC) (i) Open Access

\begin{abstract}
Total phenolics, anthocyanins and antioxidant capacity of five coloured/pigmented (AR2009-10, Adirondack Red, Adirondack Blue, Congo, and POROIPG22-1) and two unpigmented potato genotypes ("Anuschka" and "Russet Burbank") were assessed in fresh (with and without skin) and commercially processed/cooked/reconstituted products. Ascorbate profiles of the seven genotypes also were investigated using fresh tuber/tissue only. The results showed that genotypes greatly varied in their contents of bioactive compounds. Ascorbate profiles of the genotypes were not associated to any particular flesh colour/pigment. However, the pigmented potatoes had 1.5 to 2.5 times more the phenolics, 2 to 3 times more antioxidant capacity and higher levels of anthocyanins (13.98 to $38.57 \mathrm{mg} \mathrm{C} 3 \mathrm{GE}^{-100 \mathrm{~g}} \mathrm{FW}$ ) compared to unpigmented genotypes. No anthocyanins were detected in the unpigmented potatoes. Significant losses of total phenolics, anthocyanins and total antioxidant capacity were found during peeling $(18 \%-23 \%)$, blanching process $(40 \%-60 \%)$ and further cooking/reconstitution $(7 \%-12 \%)$ with no prominent genotype differences. Together, 65 to $90 \%$ of these bioactive compounds were lost during processing. The results suggested that pigmented potatoes contained higher amounts of total phenolics and anthocyanins and blanching step took away the most of the original bioactive compounds.
\end{abstract}

\section{Keywords}

Potato, Phenolics, Antioxidant Capacity, Cooking, Reconstitution

\section{Introduction}

Population-based epidemiological studies have stressed the important role of diet and 
lifestyle in the emergence of many degenerative chronic diseases, such as cancers and cardiovascular diseases, in both developed and developing countries [1]. If a global health goal is to increase the amounts of vitamins, minerals or phytonutrients consumed in the diet, then a sensible approach is to further enhance the nutritional content of highly consumed crops. The nutritional value of the potato (Solanum tuberosum L.) is worth considering with regard to the high consumption of potatoes in the world and the body of evidence showing the relationship between diet and human diseases [1] [2]. Potato is currently the fourth most important crop worldwide after rice, wheat and maize with about 324 million tonnes production in 2010 [3]. The annual diet of an average global citizen in the first decade of the $21 \mathrm{st}$ century included about $33 \mathrm{~kg}$ of potatoes. In many developed countries, potato represents a secondary staple crop, with an average per capita consumption of around $75 \mathrm{~kg} \cdot \mathrm{year}^{-1}$ in 2007 [4]. In developing countries, its consumption is around $20 \mathrm{~kg} \cdot \mathrm{year}^{-1}$ per capita but rapid expansion over the past few decades has occurred in southern and eastern Asia [4]. In the Andes of South America, the potato consumption can reach $250 \mathrm{~kg} \cdot \mathrm{year}^{-1}$ per capita. In these regions, potato constitutes the main staple crop, and most households cultivate 10-12 varieties in order to reduce their vulnerability to environmental conditions [5].

Potato is an exceptionally high-yielding carbohydrate-rich crop and much of the world's production is occupied by modern yellow-and white-fleshed potatoes. Other notable features are a high-quality protein, a significant level of vitamin C [6] [7] [8] that contributes substantially to the Recommended Daily Allowance [8], also certain minerals such as potassium, phosphorus, and magnesium [5]. Beyond these basic nutrients, less well known are significant amounts of bioactive compounds (including phenolics and carotenoids) in potato which are potent antioxidants [9] [10].

Promising routes for enhancing the quality of staple crops include biotechnologies and conventional plant breeding. Although some efforts to improve potato carotenoid [11] or phenolic contents [12] are currently made through transgenic approaches, natural variations in the potato germplasm may also offer nutritionally interesting potato genotypes. Of particular interest are the native Andean potato landraces (pigmented potatoes). Andean potato landraces are extremely diverse as compared to modern potato varieties, ranging from diploids to pentaploids; a wide variability in tuber shape, flesh and skin color, and flavour; in storage and cooking quality [10] [12] [13] and, so far, are largely unexplored from nutritional point of view.

One study has shown that antioxidant values (ORAC) for red-fleshed types reached as high as $300 \%$, while for purple-fleshed types reached $250 \%$ of the white-fleshed genotypes [14]. Lechman et al. [7] found high variability in anthocyanin contents and antioxidant capacity (ABTS, FRAP and DPPH test) among 30 diverse coloured genotypes. The purple-fleshed clones were among the top. Lewis et al. [15] found that cultivated potato tuber peel contained 2000 - $5000 \mu \mathrm{g}$ per g FW phenolic acids and $200-300$ $\mu \mathrm{g}$ of flavonoids. Purple- and red-fleshed tubers contained three to four times the concentration of phenolic acids and had twice the flavonoid concentration of white-fleshed genotypes. Lewis et al. [15] also found much higher concentrations of anthocyanins in certain genotypes extending up to $368 \mathrm{mg}$ per $100 \mathrm{~g} \mathrm{FW}$ in the purple-fleshed and up to $22 \mathrm{mg}$ per $100 \mathrm{~g} \mathrm{FW}$ in red-fleshed types. Concentrations were considerably higher in 
peel, approaching $900 \mathrm{mg}$ in purple-fleshed and $500 \mathrm{mg}$ in red-fleshed types per $100 \mathrm{~g}$ FW (of the peel alone).

Given that potato is not consumed fresh by humans, it is fundamental to measure the bioactive compounds after cooing. However, other than domestic cooking; there is little published information on the effects of commercial cooking/processing on its constituents (except vitamin C) particularly in different colour-fleshed potatoes. Physical and/or chemical (degradation or losses of sensitive nutrients) alterations are possible depending on methods used to process potatoes [6] [16] [17] and obtaining processed products that keep more of their original characteristics are one of the most tangible challenges in potato processing industry, because of their content of antioxidant metabolites which are readily prone to thermal degradation. If a substantial amount of potato bioactive components survive cooking, then introducing new genotypes with even higher amounts would be a logical approach to boosting dietary intake.

There are contradictory reports on the effects of cooking on bioactive compounds of potato in the literature. A number of studies have charted the loss of vitamin $\mathrm{C}$ during diverse cooking and processing steps. In a review, Brown [18] reported that $20 \%$ to $45 \%$ of vitamin $\mathrm{C}$ is lost due to diffusion into the water bath during blanching (an important part of pre-cooked French fry production) and processing of potato into flakes almost totally eradicated vitamin C. Other studies have shown that different cooking treatments reduce various phenolic compounds in potatoes [6] [16] [19]. One study examining the effects of cooking procedures on mature potatoes showed that baking in an oven at $212^{\circ} \mathrm{C}$ for $45 \mathrm{~min}$, boiling in water for $30 \mathrm{~min}$, or microwaving at $218^{\circ} \mathrm{C}$ for 30 min, decreased chlorogenic acid to $0 \%, 35 \%$, and $55 \%$ of the original amount, respectively [20].

In contrast, scientifically optimized microwaving $(2 \mathrm{~min} 30 \mathrm{~s}$ at high in an $1100 \mathrm{~W}$ microwave), baking $\left(375^{\circ} \mathrm{C}\right.$ for $\left.30 \mathrm{~min}\right)$, boiling $(18 \mathrm{~min})$, steaming $(15 \mathrm{~min})$ and stirfrying in cold-pressed canola oil (18 min) of developmentally young (small sized) potatoes of three genotypes resulted in an increase in recoverable amounts of the total phenolics, chlorogenic acids, rutin, kaempferol-rutinose, vitamin $\mathrm{C}$ and antioxidant activities [8]. Other studies showed an increase in most of the individual phenolic compounds and antioxidant activity cooked by baking, frying and microwaving when compared to uncooked tuber samples [7] [8]. However, published data on the extent of variation with regard to phytonutrient contents in commercially processed potato products especially within the colour-fleshed potatoes are scarce.

Aims of this study were to quantify the bioactive components (ascorbate, total antioxidants, total phenolics and anthocyanin) of seven potato genotypes and selections and evaluate how the commercial processing methods and subsequent freezing and final reconstituted cooking methods affect their bioactive components.

\section{Materials \& Methods}

\subsection{Potato Genotypes}

Seven potato genotypes were used in this study. Name, flesh colour, average tuber size and dry matter content of the genotypes are presented in Table 1 and Figure 1 . Among those, Adirondack Red, Adirondack Blue and AR2009-10 were Agriculture and Agri- 


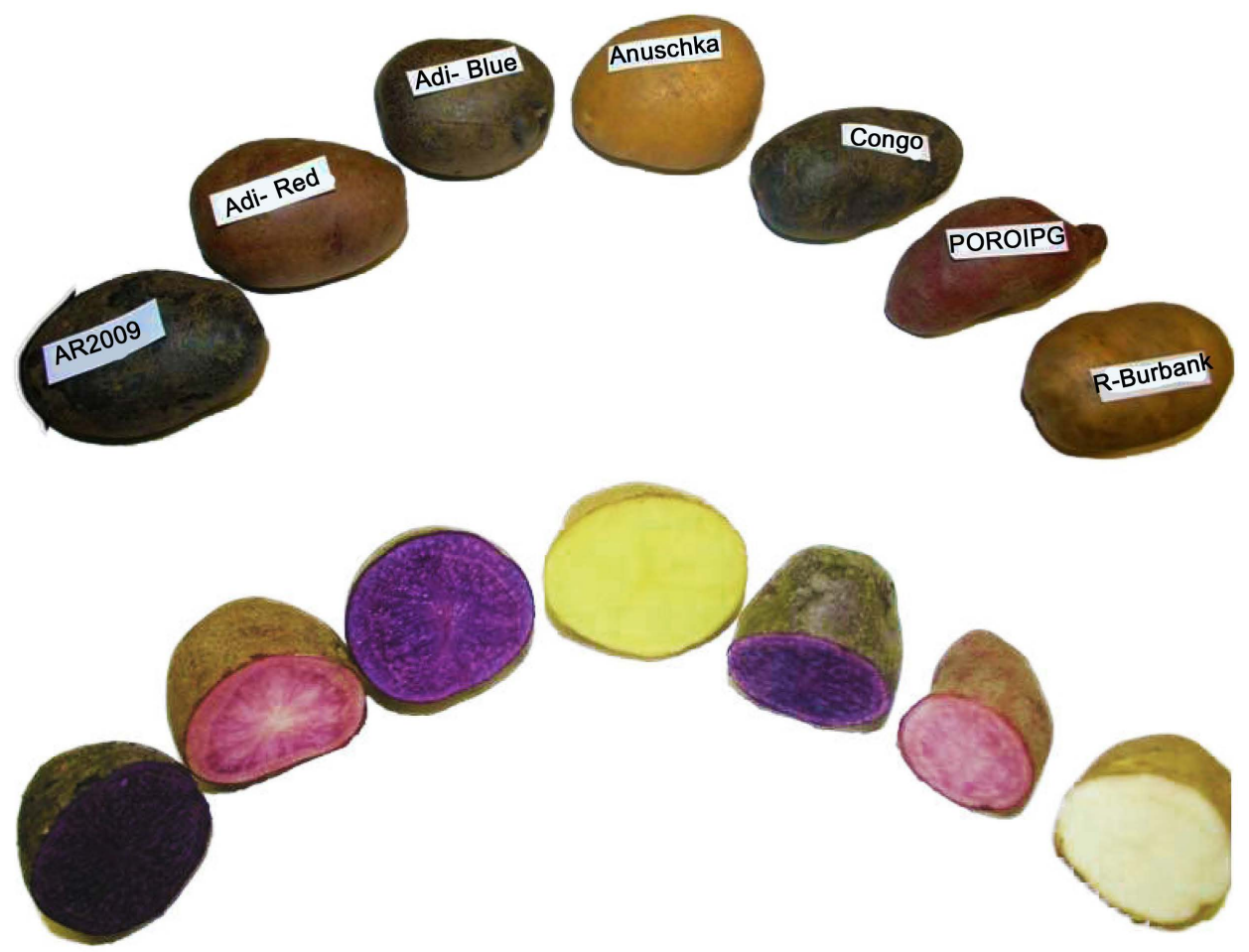

Figure 1. Skin and flesh colour of the potato genotypes. Potato genotypes: Clockwise from the left; AR2009-10 (recently registered as "AAC Blue Steele"), Adirondack Red, Adirondack Blue, Anuschka, Congo, POROIPG22-1, and Russet Burbank.

Table 1. Name, flesh colour, average tuber size and dry matter content of the genotypes.

\begin{tabular}{lccc}
\hline Genotype & Flesh colour & Average tuber size ${ }^{*}(\mathrm{~g} /$ tuber $)$ & Dry matter content $^{* *}(\%)$ \\
\hline AR2009-10 & Dark purple & $169 \pm 11$ & $23.24 \pm 0.58$ \\
Adirondack Red & Pink & $143 \pm 15$ & $18.59 \pm 0.33$ \\
Adirondack Blue & Blue & $128 \pm 8$ & $19.15 \pm 0.42$ \\
Anuschka & Yellowish & $163 \pm 14$ & $18.45 \pm 0.25$ \\
Congo & Purple & $136 \pm 6$ & $22.11 \pm 0.68$ \\
POROIPG22-1 & Pink & $98 \pm 10$ & $20.46 \pm 0.63$ \\
Russet Burbank & Creamy white & $131 \pm 6$ & $20.76 \pm 0.37$ \\
\hline
\end{tabular}

${ }^{*}$ Average weight $\pm \operatorname{SE}(n=28) .{ }^{*}$ Mean dry matter content $\pm \operatorname{SE}(n=4)$.

Food Canada (AAFC) selections; POROIPG and "Anuschka" were McCain Foods Ltd. Canada selections; Congo and "Russet Burbank" were used as control. AR2009-10 has now been registered as a variety "AAC Blue Steele" in Canada.

\subsection{Field Trials}

The tubers were grown on the research farm of McCain Foods Ltd., 200 Greenfield Road, Greenfield, New Brunswick, Canada $\left(46^{\circ} 27.58^{\prime} \mathrm{N}, 67^{\circ} 38.06^{\prime} \mathrm{W}\right)$. The soil of the trial plot was predominantly Caribou gravelly silt loam series; well drained with less than 5\% slope on most of the farm; high in $\mathrm{P}$ and $\mathrm{K}$; medium in $\mathrm{Ca}^{2+}$ and $\mathrm{Mg}^{2+} ; 2.3 \%$ $2.9 \%$ organic matter and $5.5-6.8 \mathrm{pH}$. 
On 25 May 2012, plots were staked off in the field and furrows opened and fertilizer (16-9-30 3B at $\left.200 \mathrm{~kg} \cdot \mathrm{ha}^{-1}\right)$ banded using a modified pea planter. Cut seeds $(\sim 60 \mathrm{~g}$ in weight) of the seven genotypes were hand dropped at $30-40 \mathrm{~cm}$ spacing in $9 \mathrm{~m}$ long rows for each genotype. Each plot $\left(9.0 \mathrm{~m} \times 1.82 \mathrm{~m}=16.38 \mathrm{~m}^{2}\right)$ consisted of two rows at $91 \mathrm{~cm}$ apart. Seeds were covered using disks mounted to a tractor. The plots were arranged in a randomized complete block design with four replications. Hilling was completed once 20 days after planting using a single pass row forming hiller. Standard pest protection measures were taken with routinely sprayed fungicides (mainly to control late blight) and insecticides (mainly to control Colorado potato beetle and flea beetles). The plants received a total of $366 \mathrm{~mm}$ of precipitation during the 120-day growth period (since 25 May to 25 September 2012). Maximum and minimum daily temperatures during the growing period ranged between $10.6^{\circ} \mathrm{C}$ to $31.3^{\circ} \mathrm{C}$ and $0.8^{\circ} \mathrm{C}$ to $19.8^{\circ} \mathrm{C}$ respectively.

On 25 September 2012, plots were harvested with a two-row potato digger and picked up by hand. After grading, the tubers were stored at the McCain Food Research Farm storage at $13^{\circ} \mathrm{C}$ and $90 \% \mathrm{RH}$. A portion of the representative tuber samples (around 25 tubers for each genotype and replicates) were shipped to AAFC, Kentville, Nova Scotia (NS) laboratory and portions of the rest tubers were processed at McCain's commercial potato processing facility [on 20 Nov. 2012 (rep 1), 22 Nov. 2012 (rep 2), 4 Jan. 2013 (rep 3) and 16 Jan. 2013 (rep 4)]. Based on types of industrial products, defined methods for processing, cooking and reconstitution were selected. Processing methods were blanching and freezing; cooking methods were microwave and frying; reconstitution methods were oven baking and frying. Combinations of these methods were made, generating five types of samples: Blanching-freezing (BF), Blanchingfreezing microwave (BFM), Blanching-frying-freezing (BFF), Blanching-frying-freezing oven (BFFO), and Blanching-frying-freezing fryer (BFFF) samples. Step by step potato processing at McCain Foods Ltd. has been presented in Figure 2. The processed samples were shipped (in dry ice) to AAFC, Kentville, NS. The samples were subsequently freeze-dried, ground and stored at $-80^{\circ} \mathrm{C}$ until further analysis.

\subsection{Tuber Storage and Tissue Sampling}

The refrigerated shipment from McCain Foods Ltd., NB, Canada of around 25 whole tubers for each genotype and replication were received at AAFC, Kentville, NS on 11 October 2012. Tubers were stored immediately at $13^{\circ} \mathrm{C}$ and at $90 \% \mathrm{RH}$. After four weeks, the storage room temperature was reduced to $12^{\circ} \mathrm{C}$. Thereafter, the temperature was reduced by $1^{\circ} \mathrm{C}$ every two weeks till it reached to $9^{\circ} \mathrm{C}$ and this temperature was maintained till the end of the study. The humidity remained always the same $(90 \% \mathrm{RH})$ until the end of the study.

\subsubsection{Initial Fresh (IF) Samples}

Initial fresh samples were processed during ascorbate analysis on 22, 23, 24 and 25th of October 2012. For ascorbate analysis, seven whole tubers were randomly selected from each genotype and replicate. The tubers were washed under tap water, dried with Kim wipes, and weighed in a tarred bowl collectively on a weighing balance and tuber mass was recorded. Then two $1 \mathrm{~cm}$ thick coins were cut from the central portion from each 
$\underline{\text { Steps }}$

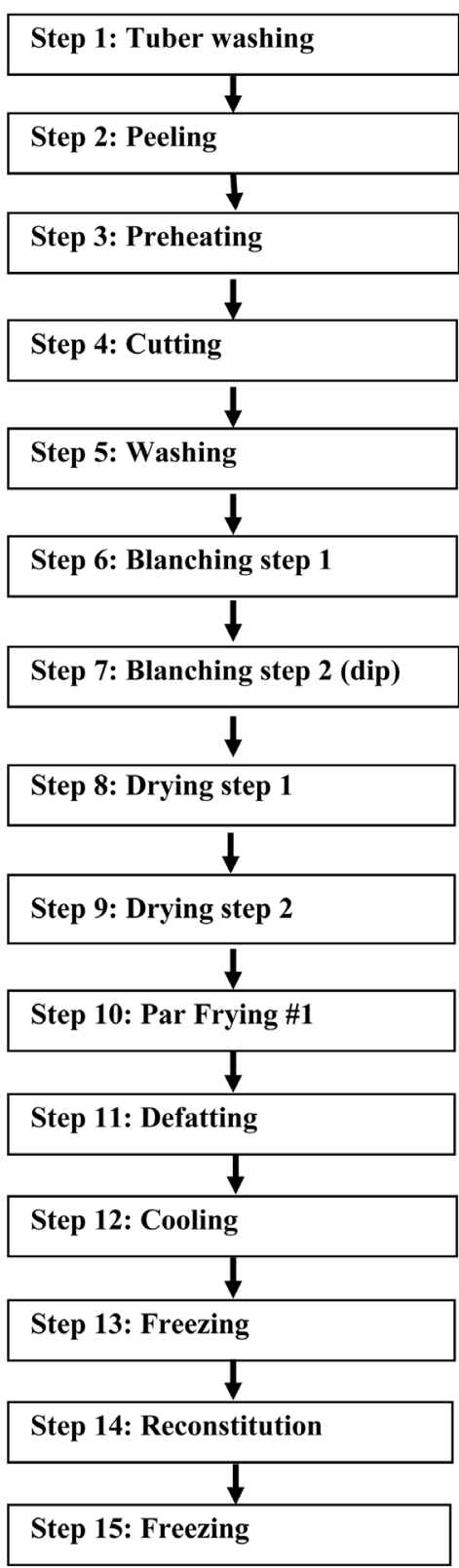

\section{Procedure}

Under running water

Equipment: Hobart 6430

Equipment: Quest blancher; $40 \mathrm{~min}$ at $55^{\circ} \mathrm{C}$

Equipment: Urschel; either $3 / 8$ " $\times 3 / 8$ ", straight cut or $1 \times 3 / 4 \times 5 / 8$ " cube

1 min under cold running water

Equipment: Quest blancher; $15 \mathrm{~min}$ at $75^{\circ} \mathrm{C}$

Equipment: Quest blancher; 1 min at $65^{\circ} \mathrm{C}$, with addition of $0.8 \%$ Sodium Acid Pyrophosphate (SAPP)

Equipment: Binder FED 720 with large capacity fan; 8 min at $60^{\circ} \mathrm{C}$. $100 \%$ fan speed and vent open (weight loss $5 \%-7 \%$ )

Equipment: Position dryer rack on bench top; 4 min at ambient temperature

Equipment: Frymaster split pot; $75 \mathrm{sec}$. at $180^{\circ} \mathrm{C}$ in undehydrogenated canola oil (UHC)

Shaking for $30 \mathrm{sec}$ to remove excess oil

Equipment: GRAM small unit QQ;

prechilled $-2^{\circ} \mathrm{C}$ for $8 \mathrm{~min}$

Equipment: GRAM large unit; $-25^{\circ} \mathrm{C}$

Equipment: Frymaster split pot; $15.5 \mathrm{~min}$. at $175^{\circ} \mathrm{C}$ in $\mathrm{UHC}$

Equipment: GRAM large unit; $-25^{\circ} \mathrm{C}$

Figure 2. Step by step potato processing (at MaCain Foods Ltd.) followed for this study. Note: Samples and steps involved; $\mathrm{BF}=1-9 \& 15 ; \mathrm{BFM}=1-9 \& 13-15 ; \mathrm{BFF}=1-13$; BFFO and $\mathrm{BFFM}=1-15$.

of the seven tubers. The remaining portions of the tubers were put aside. The coins were cut again at the center portion to take two $\sim 1 \mathrm{~cm}^{2}$ bars. The skin from both ends of each bar was removed. The 14 bars (from seven tubers) were chopped together into small pieces and only $5 \mathrm{~g}$ of these fresh samples were used for ascorbate analysis. Formoisture and dry matter content determination, $\sim 20 \mathrm{~g}$ of the chopped samples were placed in an oven set to $85^{\circ} \mathrm{C}$ for 72 hin pre-weighed closed paper bags. After cooling, the tissue weights were recorded. The percentage of moisture contents and dry matter were calculated as: 
$\%$ Moisture $=($ fresh weight - actual dry weight $) /$ fresh weight $\times 100$

$\%$ Dry matter $=($ actual dry weight $/$ fresh weight $) \times 100$

The remaining portions of the seven tubers were longitudinally cut into two halves. One half was discarded and the other halves from each portion were chopped together into small pieces as ascorbate samples but including the skin. These with skin samples and the left over (without skin) samples from sacorbate analysis were thoroughly mixed together, frozen in liquid nitrogen, freeze-dried and preserved at $-80^{\circ} \mathrm{C}$ which comprised initial fresh (IF) samples. Therefore, IF samples were actually a combination of with skin $(\sim 60 \%)$ and without skin $(\sim 40 \%)$ samples.

\subsubsection{Fresh "with Skin" (FWS) and Fresh "No Skin" (FNS) Samples}

These samples were processed on $9^{\text {th }}, 10^{\text {th }}, 11^{\text {th }}$ and $22^{\text {nd }}$ of January 2013 , respectively, for Rep 1, 2, 3 and 4 (about 9 - 10 weeks after processing the initial fresh samples). For FWS and FNS samples, eight whole tubers from each genotype and rep were randomly chosen from the storage, washed and dried as described above. Each tuber was longitudinally cut into halves. Then one half was peeled using a standard kitchen peeler (at 1 $2 \mathrm{~mm}$ depth) and chopped together. The other halves were chopped together with skin. The samples were separately frozen in liquid nitrogen, freeze-dried and preserved at $-80^{\circ} \mathrm{C}$ similarly as initial fresh samples.

The above sampling produced three groups of fresh samples for each genotype. After the industrial processed samples arrived, they were freeze-dried and stored at $-80^{\circ} \mathrm{C}$ until further analysis. Together, final samples for each genotype/selection were: I) Initial fresh (IF); II) Fresh with skin (FWS); III) Fresh no skin (FNS); IV) Blanchingfreezing (BF); V) Blanching-freezing microwave (BFM);VI) Blanching-frying-freezing (BFF); VII) Blanching-frying-freezing oven (BFFO); and VIII) Blanching-frying-freezing fryer (BFFF).

\subsection{Determination of Total and Reduced Ascorbate Contents}

Ascorbate (as ascorbic acid, AsA) was extracted and analyzed using fresh potato tubers based on method developed by Bartoli et al. [21] with minor modifications. Approximately $5 \mathrm{~g}$ tissue from the finely chopped and mixed samples (mentioned above) was ground in $5 \mathrm{~mL}$ of $5 \%$ metaphosphoric acid using a pre-chilled ball mill (Teflon bowl with two zirconium balls) at 25 frequencies for $2 \mathrm{~min}$. The homogenates were decanted into a $50-\mathrm{mL}$ plastic centrifuge tube and another $10 \mathrm{~mL}$ of $5 \%$ metaphosphoric acid was used to wash the Teflon bowl and zirconium balls and decanted into the same $50 \mathrm{~mL}$ plastic centrifuge tube. The homogenates were centrifuged at $10,000 \times \mathrm{g}$ for $15 \mathrm{~min}$ at $4^{\circ} \mathrm{C}$. The supernatant was removed to a cooled clean $50 \mathrm{~mL}$ plastic centrifuge tube and placed on ice. For reduced ascorbate determination, a $200 \mu \mathrm{L}$ supernatant aliquot was combined with $1000 \mu \mathrm{L}$ of $150 \mathrm{mM}$ phosphate buffer ( $\mathrm{pH} 7.4 ; 5 \mathrm{mM}$ EDTA) and $200 \mu \mathrm{L}$ of Milli-Q water (Millipore, Bedford, MA). For total ascorbate, the same procedure was followed except that $200 \mu \mathrm{L}$ of $5 \mathrm{mM}$ dithiothreitol was substituted for $200 \mu \mathrm{L}$ of MilliQwater. The standards were prepared as per the reduced ascorbate determination, except that $200 \mu \mathrm{L}$ of each standard was substituted for the sample aliquot. Samples and standards were incubated at room temperature for $15 \mathrm{~min}$ in the dark. O-phosphoric 
acid $(100 \mu \mathrm{L})$ was added to each sample and standard to neutralize dithiothreitol and to acidify the solution for high performance liquid chromatography (HPLC) analysis. Samples were then filtered through $0.2 \mu \mathrm{m}$ polyvinylidene fluoride filters (Chromatographic Specialties Inc., Canada) fitted to a glass syringe that was rinsed three times with methanol between samples. Reduced and total ascorbates were quantified with an isocratic HPLC (Waters Corp., Milford, MA) with a C18 guard and analytical column (Luna $5 \mu \mathrm{L} 150 \times 4.6 \mathrm{~mm}$ i.d., Phenomenex, Torrance, CA). Recoveries for ascorbate spiked samples were $>95 \%$.

\subsection{Determination of Total Phenolics}

Total phenolics were extracted and analyzed based on the method developed by Singleton and Rossi [22] and Folin and Ciocalteu [23] with some modifications. Powdered freeze-dried samples for each genotype and replicate were taken from $-80^{\circ} \mathrm{C}$ and 0.250 $\mathrm{g}$ of white/yellow or $0.125 \mathrm{~g}$ of pink/purple/blue potato tissue samples were weight out in $50 \mathrm{~mL}$ centrifuge tubes. A $10 \mathrm{~mL}$ of extraction solution (40\% acetone, $40 \%$ methanol, $20 \%$ Milli-Q water and $0.1 \%$ formic acid) was added, vortexed and sonicatedat\#15 for $30 \mathrm{sec}$ and left under dim light for $30 \mathrm{~min}$. The sample was then centrifuged at 10,000 $\times$ g for 15 minand the supernatant was transferred to clean $50 \mathrm{~mL}$ centrifuge tubes and kept in fridge until use. A second extraction was done similarly and the supernatant was added together to have a $20 \mathrm{~mL}$ volume. A $25 \mu \mathrm{L}$ of standard or sample extract into 4 wells each of a 96-well microplate was used for activity assay at $750 \mathrm{~nm}$ on a Multiskan Spectrum microplate reader (Thermo Fisher Scientific, Ventaa, Finland) using $250 \mu \mathrm{L}$ Milli-Q water, $50 \mu \mathrm{L}$ Folin-Ciocalteu reagent and $12.5 \mu \mathrm{L}$ saturated $\mathrm{Na}_{2} \mathrm{CO}_{3}$. $\mathrm{Re}$ gression line was generated from the standard absorbance and used to quantitate the samples absorbance to obtain "mg.gE/g DW" (mg.gallic Acid Equivalent/g Dry Weight) values using the following formula:

(Sample $\mathrm{mg} / \mathrm{L} \times$ extraction volume $(\mathrm{L})) /$ tissue weight $(\mathrm{g})=\mathrm{mg} \cdot \mathrm{gEg}^{-1} \mathrm{DW}$

\subsection{Determination of Total Antioxidant Capacity by ORAC}

Total extraction (without separation into lipo/hydro fractions) was carried out under dim light. About $50 \mathrm{mg}$ fine ground lyophilized potato tissue was weighed into $50 \mathrm{~mL}$ centrifuge tubes and placed on ice. Then $10 \mathrm{~mL} \mathrm{70 \%} \mathrm{acetone,} \mathrm{29.5 \%} \mathrm{Milli-Q} \mathrm{water} \mathrm{and}$ $0.5 \%$ acetic acid (AWA) was added to each sample and sonicated at \#15 for 1 min with tube on ice. It was then centrifuged at $10,000 \times \mathrm{g}$ for $15 \mathrm{~min}$ and the supernatant was transferred to $25 \mathrm{~mL}$ volumetric. The extraction was repeated 2 times, each time the supernatant was transferred to the same volumetric. After the extraction, volume was brought to $25 \mathrm{~mL}$ in volumetric using AWA and kept on ice. For white and yellow tissues (for both fresh and processed samples), $300 \mu \mathrm{L}$ supernatant was removed in an eppendorf tube and $600 \mu \mathrm{L}$ AWA (room temp) was added ( $3 \times$ dilution) and vortexed. For fresh pink/purple/blue tissues, $200 \mu \mathrm{L}$ was removed in eppendorf tubes and $1000 \mu \mathrm{L}$ of AWA (room temp) was added to tube $(5 \times$ dilution) and vortexed. For processed pink/purple/blue tissues, $300 \mu \mathrm{L}$ was removed and $600 \mu \mathrm{L}$ AWA (room temp) was added $(3 \times$ dilution $)$ and vortexed. The samples were analyzed on a Fluoroskan Ascent FL 96-well microplate reader (Thermo Electron Corp., Vantaa, Finland) using 2,2'- 
azobis (2-amidinopropane) dihydrochloride (AAPH) as a peroxyl generator and 6hydroxy-2,5,7,8-tetramethylchroman-2-carboxylic acid (Trolox) as a standard according to the method developed by Prior et al. [24]. The antioxidant capacity was expressed as TE. $\mathrm{g}^{-1} \mathrm{DW}$.

\subsection{Determination of Anthocyanin}

Anthocyanins were determined based on the methods developed by Lee et al. [25] with some modifications. About $50 \mathrm{mg}$ finely ground lyophilized potato tissue was weighed into $50 \mathrm{~mL}$ centrifuge tubes. A $10 \mathrm{~mL}$ of extraction solution ( $40 \%$ acetone, $40 \%$ methanol, 20\% Milli-Q water and $0.1 \%$ formic acid) was added, vortexed and sonicated at \#15 for $30 \mathrm{sec}$ and left under dim light for $1 \mathrm{~h}$ and $30 \mathrm{~min}$ but vortexed every $10-15 \mathrm{~min}$. The sample was then centrifuged at $15,000 \times \mathrm{g}$ for $15 \mathrm{~min}$ then $8 \mathrm{~mL}$ of the supernatant was transferred into clean glass tubes and placed under flow of nitrogen. After drying, 2 $\mathrm{mL}$ of Milli-Q water was added, shaken well and transferred intopre-weighed small glass vials and placed for freeze-drying. After freeze-drying, weight of the vials were recorded again and $1 \mathrm{~mL}$ of Milli-Q water was added to each vial. Two 96-well microplates were used for each set of samples (sample $+\mathrm{pH} 1.0$ buffer; and sample $+\mathrm{pH}$ 4.5 buffer) for assay at $700 \mathrm{~nm}$ and $520 \mathrm{~nm}$ on a "Multiskan Go" microplatereader (Thermo Fisher Scientific, Ventaa, Finland). Final volume in wells was $300 \mu \mathrm{L}$. The results were expressed as $\mathrm{mg} \mathrm{C} 3 \mathrm{GE}^{-100} \mathrm{~g} \mathrm{FW}$ (Cyanidin-3-glucoside equivalents).

\subsection{Statistical Analysis}

The treatments were arranged as a two-factor (potato genotypes and cooking/recantation methods) factorial randomized complete block design with four replications. Data were subjected to analysis of variance using SAS (SAS Institute, Inc., Cary, NC). When F was significant at the $P<0.05$ level, treatment means were compared and separated using the least significant difference test (LSD). Regression analyses were performed to investigate the relationships betweenphenolics vs antioxidant capacity; anothocyanins vs total antioxidant capacity; anthocyanins vs total phenolics; and total ascorbate vs total antioxidant capacity.

\section{Results}

\subsection{Total, Reduced and 0xidized Ascorbates}

Total ascorbate $($ AsA $)$ contents significantly varied $(P<0.0001)$ between genotypes and ranged between 152 - $358 \mu \mathrm{g} \cdot \mathrm{g}^{-1} \mathrm{FW}$ with the highest content in "Anuschka", followed by Adirondack Blue (315 $\mu \mathrm{g} \cdot \mathrm{g}^{-1} \mathrm{FW}$; Figure 3(a)). The lowest amount was determined in POROIPG22-1 (152 $\left.\mu \mathrm{g} \cdot \mathrm{g}^{-1} \mathrm{FW}\right)$ followed by Adirondack Red $\left(195 \mu \mathrm{g} \cdot \mathrm{g}^{-1} \mathrm{FW}\right)$. Russet Burbank, Congo and AR2009-10 had similar and intermediate amounts of total ascorbates $\left(\sim 250 \mu \mathrm{g} \cdot \mathrm{g}^{-1} \mathrm{FW}\right)$. Reduced ascorbate contents followed similar trends among the genotypes and on average of all genotypes was about $76 \%$ of the total ascorbate (i.e. $\sim 24 \%$ oxidized ascorbate, Figure 3(a)). Regarding oxidized ascorbate, AR2009-10 had the highest amount $\left(93 \mu \mathrm{g} \cdot \mathrm{g}^{-1} \mathrm{FW}\right)$ followed by Congo $\left(74 \mu \mathrm{g} \cdot \mathrm{g}^{-1} \mathrm{FW}\right)$. Adirondack Red, POROIPG22-1, Anuschaka and Russet Burbank had the lowest amounts of oxidized ascorbates. Oxidized ascorbate content of Adirondack Blue was statistically similar with 


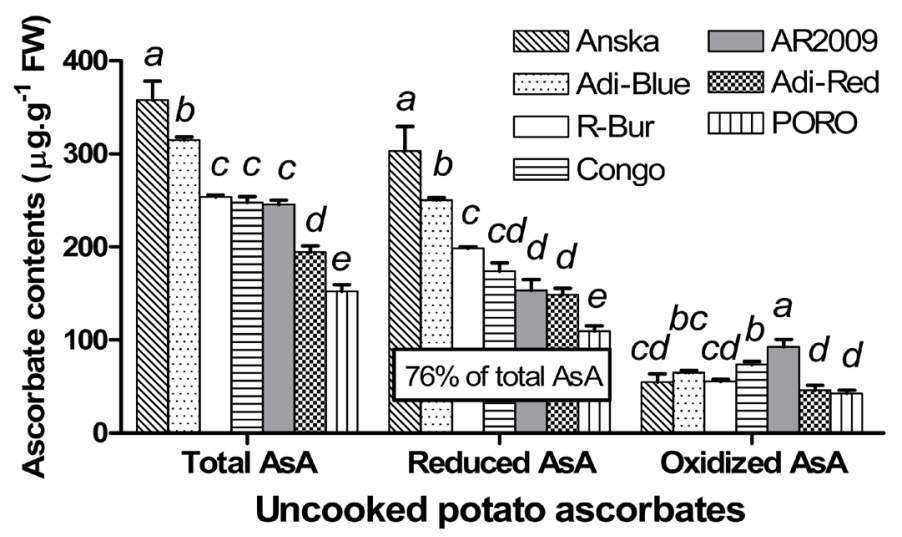

(a)

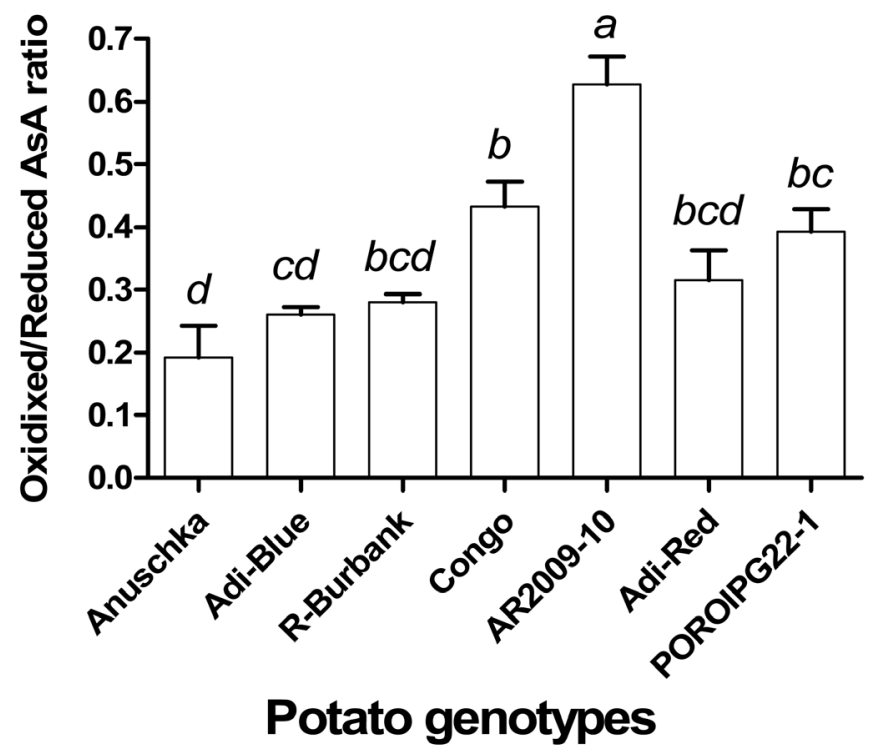

(b)

Figure 3. Total, reduced and oxidized ascorbate contents (a) and oxidized/reduced ascorbate ratio (b) of the seven potato genotypes (uncooked). The bars represent mean values of four replicates $( \pm \mathrm{SE})$. Means with different letters (within a group) are significantly different at $P<0.05$. The boxed value indicates percent of total ascorbate content.

Congo, Anuschka and Russet Burbank (Figure 3(a)). Regarding the ratio of oxidized/ reduced ascorbate, AR2009-10 had the highest oxidized/reduced ascorbate ratio followed by Congo. Anuschka had the lowest oxidized/reduced ascorbate ratio and other genotypes were statistically similar with either Anuschka or Congo (Figure 3(b)).

\subsection{Total Phenolic Contents in Fresh Potatoes}

Genotypic differences in total phenolic contents, effects of processing/reconstitution and interaction between genotype $\times$ processing were highly significant $(P<0.0001)$. Total phenolics contents in initial fresh (IF, $60 \%$ no skin, $40 \%$ with skin) samples ranged between 1.88 to $3.96 \mathrm{mg} \cdot \mathrm{g}^{-1} \mathrm{DW}$. Adirondack Blue, AR2009-10 and Adirondack Red had similar and significantly $(P<0.05)$ greater amounts compared to POROIPG22-1 and Congo. Anuschka and Russet Burbank had similar and the least mounts of total phenolics (Figure 4(a)). 


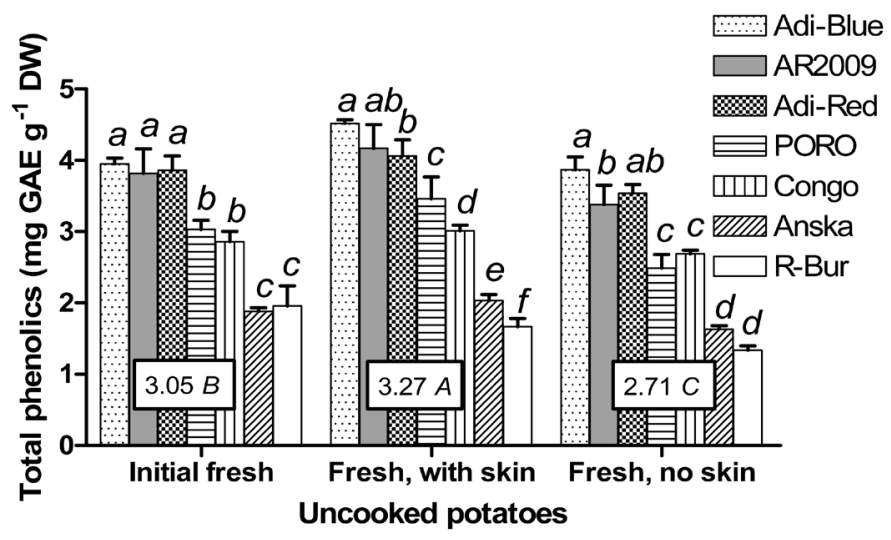

(a)

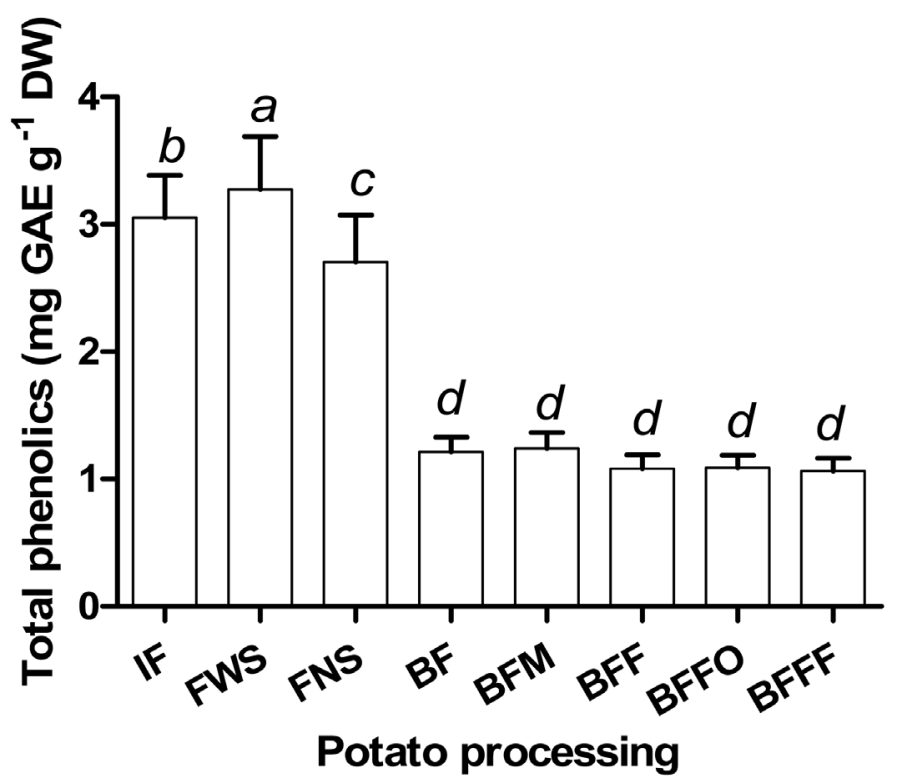

(b)

Figure 4. Total phenolics contents of the seven uncooked potato genotypes (a) and effect of cooking (average over all genotypes) on total phenolics (b). The bars represent mean values of four replicates $( \pm \mathrm{SE})$. Bars with different letters within a group are significantly different at $P<$ 0.05 . The boxed values indicate average over all genotypes. IF = Initial fresh; FWS = Fresh, with skin; FNS = Fresh, no skin; BF = Blanching-freezing; BFM = Blanching-freezing microwave; $\mathrm{BFF}=$ Blanching-frying-freezing; $\mathrm{BFFO}=$ Blanching-frying-freezing oven; BFFF = Blanching-fryingfreezing fryer.

Total phenolic contents in fresh-with skin (FWS) samples ranged between 1.67 to $4.52 \mathrm{mg} \cdot \mathrm{g}^{-1}$ DW (Figure 4(a)). In general, coloured potato genotypes (AR2009-10, Adirondack Blue, Adirondack Red, Congo and POROIPG22-1) had 1.7- to 2.5-fold greater phenolics than the yellowish/white genotypes (Anuschka and Russet Burbank). Adirondack Blue had the highest amount of phenolics $\left(4.52 \mathrm{mg} \cdot \mathrm{g}^{-1} \mathrm{DW}\right)$ and the lowest was in Russet Burbank (1.67 mg. $\mathrm{g}^{-1} \mathrm{DW}$ ). However, the content in AR2009-10 was statistically similar with Adirondack Blue and Adirondack Red. POROIPG22-1, Congo, Anuschka and Russet Burbank respectively, in this order, had significantly $(P<0.05)$ lower amounts of total pehnolics compared to Adirondack Blue, AR2009-10 and Adirondack Red. 
Peeling in general caused significant reduction in phenolic contents. Total phenolic contents in fresh-no skin (FNS) samples ranged between 1.34 to $3.87 \mathrm{mg} \cdot \mathrm{g}^{-1} \mathrm{DW}(11 \%$ to $28 \%$ reductions compared to FWS samples) with the highest reduction in POROIPG22-1 (28\%) followed by AR2009-10, Anuschka and Russet Burbank ( 20\% reduction). Reduction in other genotypes ranged between 11-14\% (Figure 4(a)). On average over all genotypes, FWS samples had significantly higher amounts of total pehnolics (3.27 $\left.\mathrm{mg} \cdot \mathrm{g}^{-1} \mathrm{DW}\right)$ compared to IF (3.05 $\left.\mathrm{mg} \cdot \mathrm{g}^{-1} \mathrm{DW}\right)$ and IF samples had significantly greater total phenolics compared to FNS (2.71 $\left.\mathrm{mg} \cdot \mathrm{g}^{-1} \mathrm{DW}\right)$ samples.

\subsection{Effect of Processing/Cooking/Reconstitution on Total Phenolics}

In this study, we aimed at investigating the effects of processing/cooking/reconstitution, therefore, the data were averaged over all genotypes. It was found that fresh with skin (FWS) samples had the highest value at $3.27 \mathrm{mg} \cdot \mathrm{g}^{-1} \mathrm{DW}$ total phonolics (Figure 4(b)). Initial fresh (IF) and fresh no skin (FNS) samples had, respectively, 7 and 18\% lesser phenolics compared to FWS samples which were statistically significant $(P<$ 0.05; Figure 4(b)). Cooking/reconstitution of the potatoes, blanching-freezing (BF) in particular, eliminated about $65 \%$ phenoics compared to FWS (and 58\% compared to FNS). Further cooking/reconstitution processes (microwave, frying, oven and fryer) did not cause additional reductions in phenolic contents (Figure 4(b)).

\subsection{Effect of Processing/Cooking/Reconstitution on Phenolics of Individual Genotype}

Regarding individual genotypes, phenolic contents in IF and FWS samples did not differ significantly $(P>0.05)$ in most genotypes except for Adirondack Blue and POROIPG22-1. However, peeling (FNS samples) caused significant $(P<0.05)$ amount of phenolic losses (compared to FWS) in most genotypes except for Congo and Russet Burbank (Table 2(a)).

Blanching removed most of the pehnolics in all genotypes with little or no further reductions with further processing/reconstitution, except for Congo. Congo had kept significantly $(P<0.05)$ greater $(\sim 7 \%)$ amounts of phenolics in BF samples compared to other cooking/reconstitution methods (Table 2(a)). In general, genotypes with greater initial levels of phenolics (coloured genotypes) lost more ( $65 \%)$ and genotypes those had less phenolics to start with (Anuschka and Russet Burbank), lost less ( 50\%) to cooking/reconstitution (Table 2(a)).

\subsection{Anthocyanin Contents in Fresh Potatoes}

All genotypes were analysed for anthocyanin contents, however, no anthocyanins were detected in Anuschka (yellowish flesh) and Russet Burbank (creamy white flesh). Therefore, anthocyanin data have been presented excluding Anuschka and Russet Burbank (Table 2(a), Figure 5). Genotypic differences in anthocyanin contents, effects of processing/reconstitution and interaction between genotype $\times$ processing were highly significant $(P<0.0001)$. In initial fresh (IF) samples, AR2009-10 had the highest amount of anthocyanins followed by Adirondack Blue and Adirondack Red andPOROIGP22-1 had significantly lower anthocyanins compared to Adirondack Red, how- 
Table 2. (a) Effect of potato processing/cooking on total phenolics and anthocyanins of individual potato genotypes; (b) Effect of potato processing/cooking on total antioxidant capacity of individual potato genotypes.

(a)

\begin{tabular}{|c|c|c|c|c|c|c|c|c|c|c|c|c|}
\hline \multirow[b]{2}{*}{$\begin{array}{l}\text { Potato } \\
\text { processing/ } \\
\text { cooking }\end{array}$} & \multicolumn{7}{|c|}{ Total phenolics $\left(\mathrm{mg} \cdot \mathrm{g}^{-1} \mathrm{DW}\right)$} & \multicolumn{5}{|c|}{$\begin{array}{l}\text { Total anthocyanins } \\
\left(\mathrm{mg} \mathrm{C} 3 \mathrm{GE}^{-100 \mathrm{~g}} \mathrm{FW}\right)\end{array}$} \\
\hline & 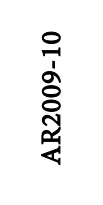 & 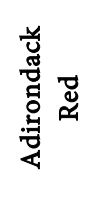 & 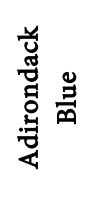 & $\begin{array}{l}\text { 品 } \\
\text { ¿̊ }\end{array}$ & 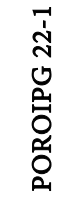 & 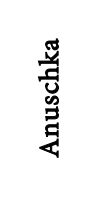 & 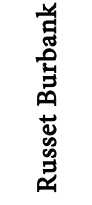 & 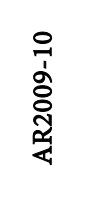 & 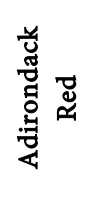 & 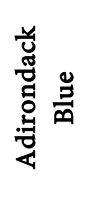 & $\begin{array}{l}\text { : } \\
\text { ¿̊ } \\
0\end{array}$ & 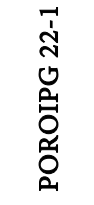 \\
\hline IF & $3.83 a b$ & $3.86 a b$ & $3.96 b$ & $2.86 a$ & $3.04 b$ & $1.88 a b$ & $1.96 a$ & $33.66 b$ & $14.79 a$ & $22.39 a$ & $11.52 a$ & $13.36 a$ \\
\hline FWS & $4.17 a$ & $4.06 a$ & $4.52 a$ & $3.01 a$ & $3.46 a$ & $2.03 a$ & $1.67 a b$ & $38.57 a$ & $15.05 a$ & $23.80 a$ & $13.98 a$ & $14.82 a$ \\
\hline FNS & $3.38 b$ & $3.54 b$ & $3.88 b$ & $2.69 a$ & $2.49 c$ & $1.63 b$ & $1.34 b$ & $30.50 c$ & $12.61 a$ & $20.95 a$ & $11.39 a$ & $11.12 b$ \\
\hline $\mathrm{BF}$ & $1.35 c$ & $1.54 c$ & $1.53 c$ & $1.74 b$ & $1.07 d$ & $0.88 c$ & $0.80 c$ & $5.07 d$ & $2.73 b$ & $7.87 b$ & $2.52 b$ & $2.10 c$ \\
\hline BFM & $1.29 c$ & $1.61 c$ & $1.67 c$ & $1.30 c$ & $1.12 d$ & $0.88 c$ & $0.83 c$ & $4.40 d$ & $2.65 b$ & $3.26 c$ & $2.58 b$ & $2.10 c$ \\
\hline BFF & $1.24 c$ & $1.36 c$ & $1.41 c$ & $1.11 c$ & $1.01 d$ & $0.76 c$ & $0.69 c$ & $3.15 d$ & $1.72 b$ & $2.81 c$ & $1.41 b$ & $1.55 c$ \\
\hline BFFO & $1.20 c$ & $1.42 c$ & $1.34 c$ & $1.12 c$ & $1.03 d$ & $0.76 c$ & $0.76 c$ & $2.76 d$ & $1.54 b$ & $2.54 c$ & $1.08 b$ & $1.43 c$ \\
\hline BFFF & $1.17 c$ & $1.37 c$ & $1.35 c$ & $1.15 c$ & $0.97 d$ & $0.72 c$ & $0.71 c$ & $2.60 d$ & $1.53 b$ & $2.72 c$ & $1.12 b$ & $1.22 c$ \\
\hline
\end{tabular}

(b)

\begin{tabular}{|c|c|c|c|c|c|c|c|}
\hline \multirow[b]{2}{*}{$\begin{array}{l}\text { Potato } \\
\text { processing/ } \\
\text { cooking }\end{array}$} & \multicolumn{7}{|c|}{ Total antioxidant capacity $\left(\mathrm{TE} \cdot \mathrm{g}^{-1} \mathrm{DW}\right)$} \\
\hline & 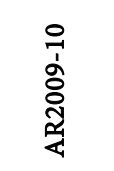 & 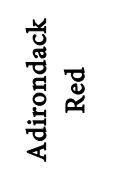 & 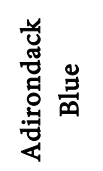 & $\begin{array}{l}\text { 品 } \\
\text { : }\end{array}$ & ํㅕㅁ & 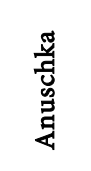 & 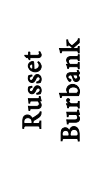 \\
\hline IF & $88.82 a b$ & $100.52 b$ & $93.30 b$ & $65.14 a b$ & $79.28 b$ & $30.81 a$ & $28.86 b$ \\
\hline FWS & $94.57 a$ & $109.51 a$ & $107.48 a$ & $73.99 a$ & $96.62 a$ & $35.27 a$ & $43.11 a$ \\
\hline FNS & $81.41 b$ & $90.81 b$ & $90.78 b$ & $58.74 b$ & $65.50 c$ & $26.87 a$ & $27.32 b$ \\
\hline $\mathrm{BF}$ & $39.86 c$ & $57.14 c$ & $44.48 c$ & $34.84 c$ & $33.39 d$ & $15.19 b$ & $14.70 c$ \\
\hline BFM & $34.33 c d$ & $52.70 c$ & $46.93 c$ & $34.84 c$ & $35.21 d$ & $16.74 b$ & $15.94 c$ \\
\hline BFF & $26.00 d$ & $39.63 d$ & $34.88 d$ & $26.98 c$ & $28.29 d$ & $16.72 b$ & $9.45 c$ \\
\hline BFFO & $29.36 d$ & $35.73 d$ & $34.50 d$ & $24.43 c$ & $28.07 d$ & $10.20 b$ & $10.24 c$ \\
\hline BFFF & $25.90 d$ & $33.56 d$ & $32.21 d$ & $24.33 c$ & $25.69 d$ & $10.28 b$ & $10.96 c$ \\
\hline
\end{tabular}

Note: Means with different lower case letters in a column are significantly different at $P<0.05 . \mathrm{IF}=$ Initial fresh; FWS $=$ Fresh, with skin; FNS = Fresh, no skin; BF = Blanching-freezing; BFM = Blanching-freezing microwave; BFF = Blanching-frying-freezing; $\mathrm{BFFO}=$ Blanching-frying-freezing oven; $\mathrm{BFFF}$ = Blanching-frying-freezing fryer.

ever, contents in Congo were the lowest (Figure 5(a)). Anthocyanin contents in freshwith skin (FWS) samples ranged between 13.98 to $38.57 \mathrm{mg} \mathrm{C} \mathrm{GE}^{-100 \mathrm{~g}} \mathrm{FW}$ (Figure 5(a)) with the highest amount in AR2009-10 (38.57 $\mathrm{mg} \mathrm{C} \mathrm{GE}^{-100 g} \mathrm{FW}$ ) followed by Adirondack Blue (23.80 mg C3GE $\left.{ }^{-100 g} \mathrm{FW}\right)$. AdirondackRed, POROIGP22-1 and Congo had similar and the lowest amounts of anthocyanins ( $\left.14.5 \mathrm{mg} \mathrm{C}^{\mathrm{G}} \mathrm{GE}^{-100 \mathrm{~g}} \mathrm{FW}\right)$. Trends in fresh-no skin (FNS) samples were similar to that of FWS samples (Figure 5(a)). On average over all genotypes, FWS samples had the highest (21.24 mg 


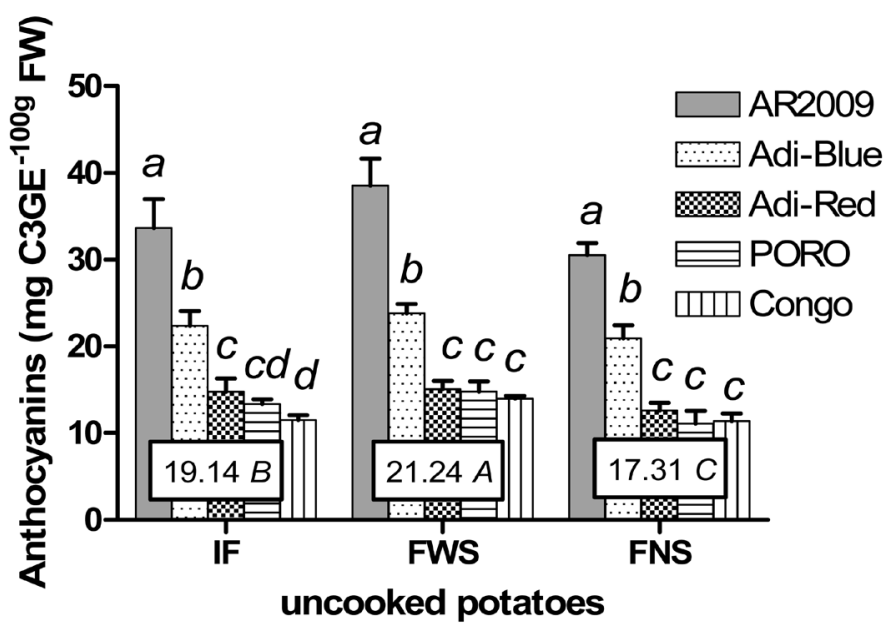

(a)

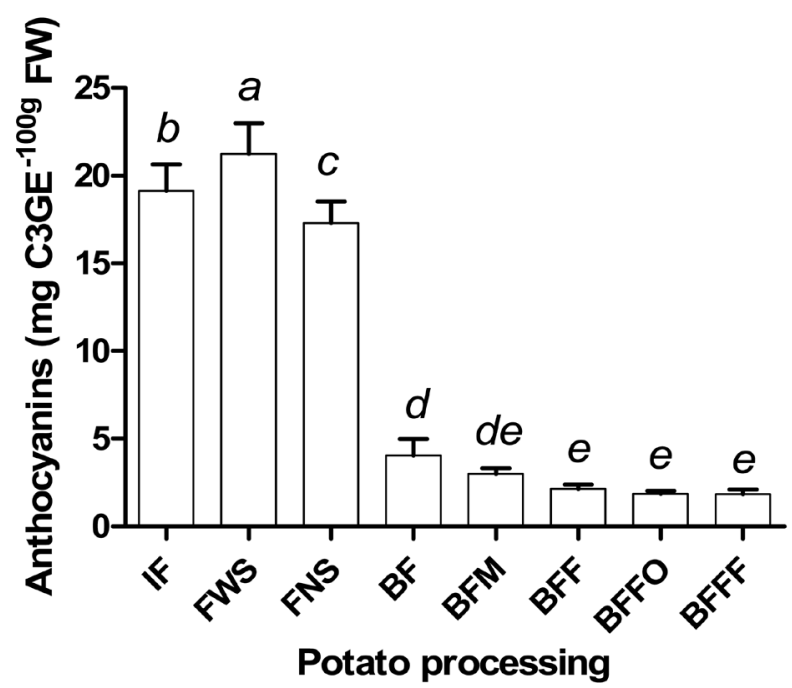

(b)

Figure 5. Anthocyanin contents in five uncooked coloured-flesh potato genotypes (a) and effect of cooking (b) on anthocyanins (average over all genotypes). The bars represent mean values of four replicates $( \pm \mathrm{SE})$. Bars with different letters within a group are significantly different at $P<$ 0.05. The boxed values indicate average over all genotypes. IF = Initial fresh; FWS = Fresh, with skin; FNS = Fresh, no skin; BF = Blanching-freezing; BFM = Blanching-freezing microwave; $\mathrm{BFF}=$ Blanching-frying-freezing; $\mathrm{BFFO}=$ Blanching-frying-freezing oven; BFFF $=$ Blanching-fryingfreezing fryer.

C3 $3 E^{-100 g} \mathrm{FW}$ ) anthocyanins. Initial fresh (IF) and FNS samples had, respectively, 10\% and $19 \%$ lesser anthocyanins compared to FWS samples which were statistically significant $(P<0.05$; Figure 5(b)).

\subsection{Effect of Processing/Cooking/Reconstitution on Anthocyanin Contents}

On average over all genotypes, cooking/reconstitution of the potatoes, blanching in particular (BF), eliminated about $81 \%$ the anthocyanins compared to FWS samples (and 77\% compared to FNS). Further cooking/reconstitution processes (BFF, BFFO and BFFF), similarly and significantly $(P<0.05)$ promoted further reductions $(\sim 10 \%$ 
more) compared to BF samples (Figure 5(b)). Anthocyanins in BFM samples were statistically similar with the BF samples and also were not significantly different from the $\mathrm{BFF}, \mathrm{BFFO}$ and BFFF samples.

\subsection{Effect of Processing/Cooking/Reconstitution on Anthocyanins of Individual Genotype}

Regarding individual genotypes, peeling (FNS) did not significantly $(P>0.05)$ reduce anthocyanins in other genotypes except for AR2009-10 and POROIPG22-1 (Table 2(a)). Regarding initial fresh (IF) samples, only AR2009-10 had significantly $(P<0.05)$ lesser amount of anthocyanins compared to FWS samples (Table 2(a)). Nevertheless, it possessed the highest amounts of anthocyanins in fresh samples compared to all the other four genotypes. Cooking/reconstitution processes, blanching in particular, greatly eliminated anthocyanins in all genotypes with no further reductions with further processing/reconstitution except for Adirondack Blue. Adirondack Bluehad significantly $(P<0.05)$ greater $(\sim 7 \%)$ amounts of anthocyanins in BF samples compared to other cooking/reconstitution methods (Table 2(a)).

\subsection{Total Antioxidant Capacity of Fresh Potatoes}

Genotypic differences in total antioxidant capacity, effects of processing/cooking/reconstitution and interaction between genotypes $\times$ processing were highly significant $(P<0.0001)$. In general, pigmented genotypes (AR2009-10, Adirondack Blue, Adirondack Red, Congo and POROIPG22-1) had 2- to 3-fold greater antioxidant capacities than the unpigmented genotypes (Anuschka and Russet Burbank; Figure 6(a)). Total antioxidant capacity in initial fresh (IF) samples ranged between 31 to $101 \mathrm{TE} \mathrm{g}^{-1} \mathrm{DW}$. Adirondack Red had greater antioxidant capacity compared to AR2009-10. However, antioxidant capacity of Adirondack Blue was not significantly $(P>0.05)$ different from Adirondack Red and AR2009-10. Congo and POROIPG22-1, in this order respectively, had significantly $(P<0.005)$ lower antioxidant capacity compared to Adirondack Red, AR2009-10 and Adirondack Blue. Russet Burbank and Anuschka had similar and significantly $(P<0.005)$ lower antioxidant capacity compared to all five other genotypes (Figure 6(a)).

Total antioxidant capacity in fresh-with skin (FWS) samples ranged between 35 to $110 \mathrm{TE} \cdot \mathrm{g}^{-1} \mathrm{DW}$. Adirondack Red and Adirondack Blue had similar and the highest antioxidant capacity followed by POROIPG22-1 and AR2009-10 ( $\left.95 \mathrm{TE} \cdot \mathrm{g}^{-1} \mathrm{DW}\right)$.Congo, Russet Burbank and Anuschka, in this order, respectively had significantly $(P<0.05)$ lower antioxidant capacity compared to other genotypes (Figure 6(a)). Fresh-no skin (FNS) potatoes had significantly $(P<0.05)$ lesser antioxidant capacity compared to fresh-with skin (FWS) potatoes and ranged between 27 to $92 \mathrm{TE} \cdot \mathrm{g}^{-1} \mathrm{DW}$ (Figure 6(a)). Maximum loses were recorded in POROIPG22-1 and Russet Burbank ( 35\%) and the least reductions were recorded in AR2009-10, Adirondack Blue and Adirondack Red $(\sim 16 \%)$. On average over all genotypes, total antioxidant capacity of FWS samples was $80 \mathrm{TE} \cdot \mathrm{g}^{-1} \mathrm{DW}$. About $21 \%$ antioxidant capacity was lost due to peeling. Initial fresh (IF) samples had about $13 \%$ lesser antioxidant capacity compared to FWS samples which were statistically significant $(P<0.05$; Figure 6(a)). 


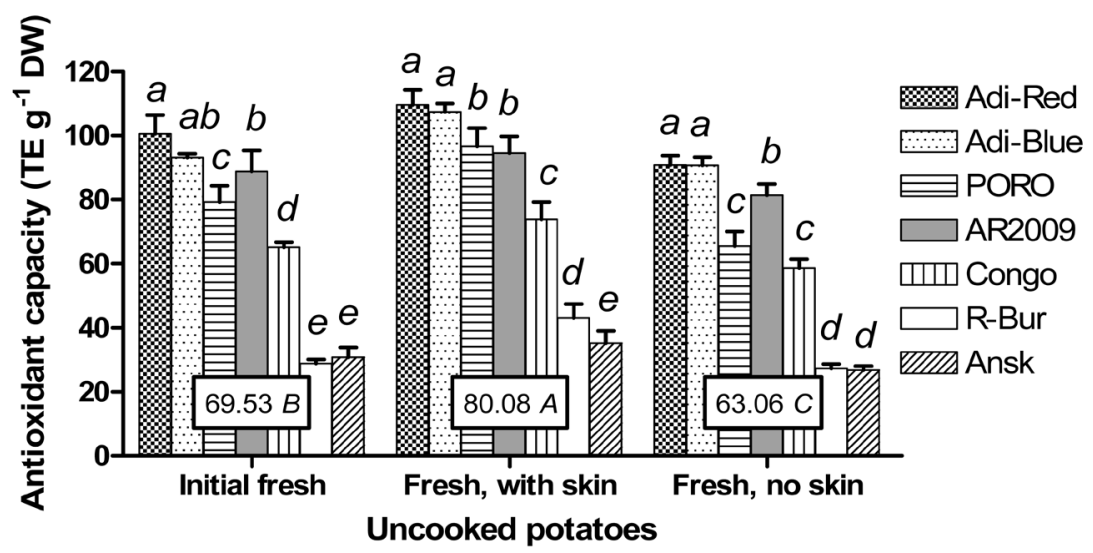

(a)

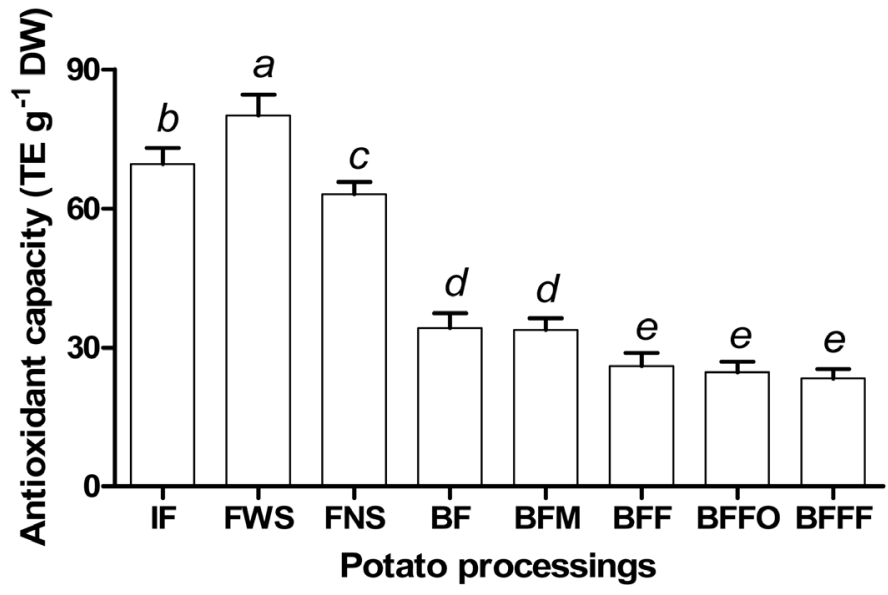

(b)

Figure 6. Total antioxidant capacity of seven uncooked potato genotypes (a) and effect of cooking (b) on total antioxidant capacity (average over all genotypes). The bars represent mean values of four replicates $( \pm \mathrm{SE})$. Bars with different letters within a group are significantly different at $P<$ 0.05 . The boxed values indicate average over all genotypes. IF = Initial fresh; FWS = Fresh, with skin; FNS = Fresh, no skin; BF = Blanching-freezing; BFM = Blanching-freezing microwave; $\mathrm{BFF}=$ Blanching-frying-freezing; $\mathrm{BFFO}=$ Blanching-frying-freezing oven; $\mathrm{BFFF}=$ Blanchingfrying-freezing fryer.

\subsection{Effect of Processing/Cooking/Reconstitution on Total Antioxidant Capacity}

On average over all genotypes, blanching alone (BF samples) reduced $58 \%$ antioxidant capacity compared to FWS samples (45\% compared to FNS samples).Further cooking/ reconstitutions (BFF, BFFO and BFFF), also similarly and significantly $(P<0.05)$ reduced total antioxidant capacity ( 12\%) except for BFM processing (Figure 6(b)).

\subsection{Effect of Processing/Cooking/Reconstitution on Antioxidant Capacity of Individual Genotype}

Regarding individual genotypes, peeling (FNS) significantly $(P<0.05)$ reduced total antioxidant capacity in all genotypes except Anuschka. Total antioxidant capacity of IF samples were significantly $(P<0.05)$ lesser in most genotypes compared to FWS samples except AR2009-10, Congo and Anuschka (Table 2(b)). 
Blanching greatly reduced total antioxidant capacity in all genotypes with some differences among them. Further cooking/reconstitution did not cause further reductions in antioxidant capacity except for Adirondack Red, Adirondack Blue and AR2009-10 (Table 2(b)). BF samples of these three genotypes had about $13 \%$ more antioxidant capacity compared to BFF, BFFO and BFFF samples. However, as contrary to the total phenolics, genotypes with greater initial levels(pigmented genotypes) and genotypes with lesser initial levels (Anuschka and Russet Burbank); similarly lost about $65 \%$ of the total antioxidant capacity to blanching and further cooking/reconstitution (Table 2(b)).

\subsection{Bioactive Compounds Loses Due to Processing and Relationships between Total Phenolics, Anthocyanins, Total Antioxidant Capacity and Total Ascorbates}

On average over all genotypes, $\sim 65 \%$ of the total phenolics were lost during potato processing. Of which, $\sim 18 \%$ was lost to peeling, $40 \%$ to blanching and $\sim 7 \%$ was lost during further cooking/reconstitution (BFM, BFF, BFFW, BFFF). About $90 \%$ of the anthocyanins were lost during potato processing. Of which about $20 \%$ was lost to peeling, $\sim 60 \%$ to blanching and $\sim 10 \%$ was lost during further cooking/reconstitution. While about $70 \%$ of the total antioxidant capacity were lost during potato processing. Of which, about $\sim 23 \%$ was lost to peeling, $\sim 35 \%$ to blanching and $\sim 12 \%$ was lost during further cooking/reconstitution (Figure $7(\mathrm{a})$ ).

The results showed that there were highly significant $(P<0.001)$ positive correlations between total phenolics and total antioxidant capacity (Figure 7(b)); anothocyanins and total antioxidant capacity (Figure $7(\mathrm{c})$ ); and anthocyanins and total phenolics (Figure $7(d))$. However, there were significant $(P<0.05)$ negative correlation between total ascorbate and total antioxidant capacity (Figure 7(e)).

\section{Discussion}

Total phenolics, anthocyanins and antioxidant capacity in fresh samples of five colour/pigmented and two unpigmented potato genotypes/selections were quantified and how commercial processing/reconstitution processes affect them were investigated in this study. Ascorbate profiles of the seven genotypes were also investigated using fresh tuber/tissue only (as available literatures show that there are little or no ascorbates in commercially processed potatoes). The results showed that the ascorbate profiles of the genotypes were not associated with a particular flesh colour/pigment. However, pigmented potatoes in general (with significant variations between them) contained higher levels of total pehnolics and anthocyanins compared to unpigmented genotypes. The pigmented potatoes also had higher antioxidant capacity in scavenging ORAC (oxygen radical performance capacity) radicals. The commercial processing/reconstitution processes, peeling and blanching in particular, appeared to have significant effects on phenolics, anthocyanins and antioxidant capacity as their levels were largely reduced in commercially processed/reconstituted products in all genotypes.

\subsection{Potato Genotype Differences in Bioactive Compounds}

The seven genotypes greatly varied in their contents of bioactive compounds. These 


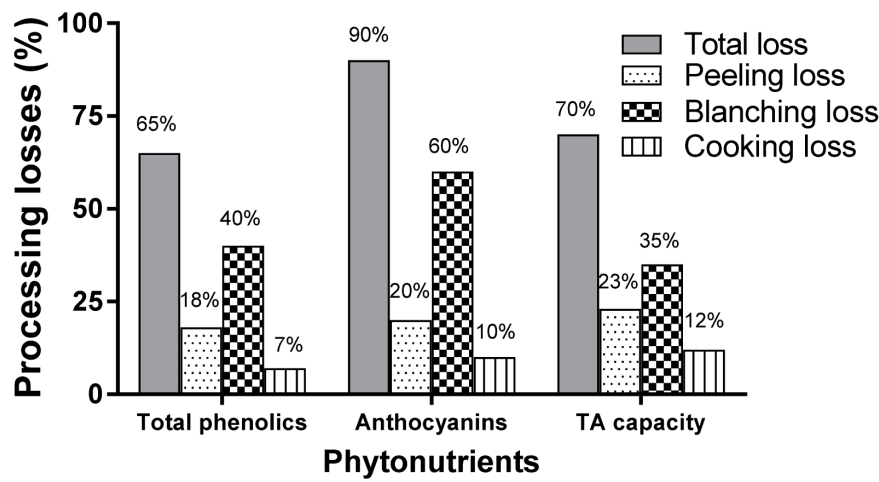

(a)

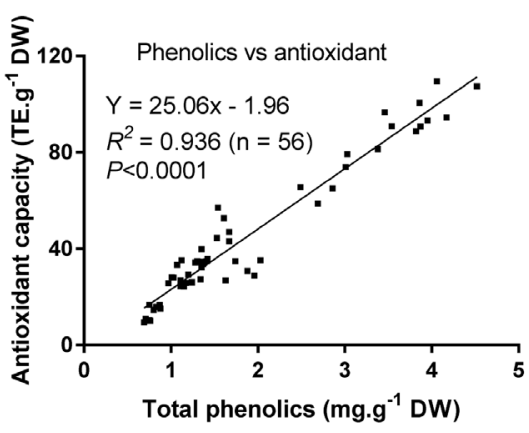

(b)

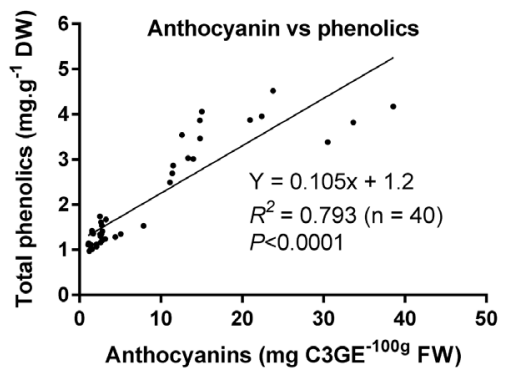

(d)

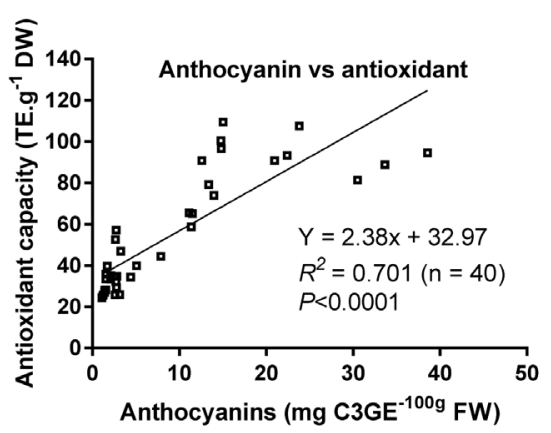

(c)

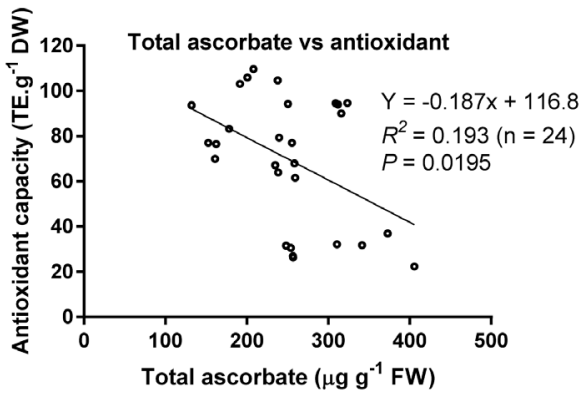

(e)

Figure 7. Losses of bioactive compounds from potatoes during possessing/cooking (a); and relationships between total phenolic contents and total antioxidant capacity (b); anthocyanin contents and total antioxidant capacity (c); total anthocyanins and phenolic contents (d); total ascorbate content and total antioxidant capacity (e) of the seven potato genotypes. TA capacity = Total antioxidant capacity.

findings are explained by the genetic variations in these genotypes. Genotype differences in bioactive components are common in vegetables and fruits as has been seen in this study. The coloured potatoes had 1.7 to 2.5 times more the phenolics presumably due to the high anthocyanins in them and about 2 to 3 times more antioxidant capacity compared to unpigmented genotypes. These findings are in consistence with [5] [17] [26] and [27] who also reported greater amounts of bioactive compounds in coloured potatoes. No anthocyanins were detected in the unpigmented potatoes however; coloured genotypes had higher levels of anthocyanins. Brown [18] and Lewis et al. [15] also reported that outside of the center of origin of cultivated potato in the Andes of South America, it is rare to find varieties with anthocyanin pigments. 
High antioxidant capacity in pigmented potatoes in our study can be explained by the presence of higher amounts of total phenolics and anothocyanins in them compared to unpigmented potato genotypes. Figures $6(\mathrm{~b})$-(d) also justify these even substantial altercations in their contents after cooking. Faller and Fialho [28] also reported positive correlations between polyphenols and antioxidant capacity in raw and cooked potatoes, carrots, onions, broccoli, and white cabbage. Lachman et al. [7] showed that total anthocyanins and individual anthocyanid corresponded to the antioxidant activity of various red and purple fleshed potatoes. Brown et al. [26] reported 330\% greater antioxidant activity in a red fleshed breeding line of potatoes than the white fleshed potato breeding lines and varieties, as has been seen in this study. Brown et al. [26] also reported that vitamin $\mathrm{C}$ may also account for up to $13 \%$ of the total antioxidant capacity of potato. Mohdaly et al. [29] also reported high antioxidant capacity as strongly related to the presence of numerous phenolic and flavonoid compounds in various vegetables and fruits. Although we did not analyze carotenoids, coloured potatoes are rich in carotenoids and are also correlated with antioxidant activity in potato tubers [26].

Under storage conditions, bioactive components of vegetables and fruits generally reduce over time. However, during the $9-10$ weeks in storage (at $13^{\circ} \mathrm{C}-9^{\circ} \mathrm{C}$ and $90 \%$ $\mathrm{RH}$ ), potato tubers seemed did not lose phenolics or antioxidant capacity significantly. The lesser amounts of phenolics in initial fresh (IF) samples (compared to FWS) were due to the combination of "with" and "without skin" samples in IF samples explained in the methodology section.

\subsection{Bioactive Compounds in Coloured Potatoes vs Berries}

Nevertheless, weighing against other researches those used similar quantification methods as performed in the present study for different kind of berries [30] [31], it was found that coloured potatoes had levels of phenoliocs, anthocyanins and antioxidant capacity that reached levels similar to those observed in strawberries and raspberries; and reached about $25 \%$ to those observed in blueberries. Ascorbate levels in coloured potatoes were similar to unpigmented genotypes, also similar to those observed in strawberries and raspberries; and about three times more than blueberries. Unlike berries, potatoes are served as part of a main course meal and, therefore, incorporation of pigmented flesh potatoes in meal can provide additional natural sources of potent antioxidants in the diet. Moreover, potatoes cost less to produce and result in higher yields that can also be economical source of raw material for extraction of anthocyanins. Along with carotenoids, anthocyanins are hydrophilic pigments responsible for the red, purple, and blue hues in most flowers, grasses, fruits, vegetables, and grains [5]. The association of coloring properties and potential health benefits in anthocyanins [32] makes them very attractive molecules for the food industry. Taken together, our results provide further evidence for the enhanced health beneficial components in pigmented potatoes. Mulinacci et al. [17] suggested that a portion (about $200 \mathrm{~g}$ raw) of these coulourful potato genotypes could consistently contribute to the daily intake of these functional compounds.

\subsection{Ascorbate Contents in Coloured Potatoes}

Ascorbate contents were not found to be associated with the tuber colour as Anuschka 
had the highest amount of ascorbate, while POROIPG22-1 had the lowest and "Russet Burbank" were somewhere in the middle with other coloured potatoes. However, AR2009-10 was recorded with the highest oxidized ascorbate contents and highest oxidized/reduced ascorbate ratio, followed by Congo (Figure 1(a) and Figure 1(b)) indicating less monodehy droascorbate reductase (MDHAR) and dehydroascorbate reductase (DHAR) activities in these genotypes, because these two enzymes are responsible for reducing the oxidated ascorbate to the reduced stage in order for its antioxidant functions..

Since total ascorbate is the sum of reduced ascorbate and oxidized ascorbate, the ascorbate pool in plants is maintained about $90 \%$ in reduced form with the remaining $10 \%$ present in the oxidized form [33]. The key aspects governing the ascorbate pool in plants are its biosynthesis, redox turnover, and degradation rates. The turnover occurs through a regenerative process. Reduced ascorbate is oxidized (by ascorbate oxidase, ascorbate peroxidase, etc. enzymes) to monodehydroascorbic acid (MDHA). MDHA is converted to reduced ascorbate through the activities of MDHAR ordispropotionates non-enzymatically to oxidized ascorbate. Oxidized ascorbate can be re-reduced back to reduced ascorbate directly through DHAR or undergoes irreversible hydrolysis to 2,3diketogulonic acid which are toxic secondary metabolites such as oxalate and tartarate [34] [35]. Therefore, MDHAR and DHAR are important enzymes contributing maintaining an appropriate level of reduced ascorbate concentration in plant cells which seemed low in genotypes AR2009-10 and Congo compared to other genotypes.

However, the overall ascorbate pool in potato tubers in our study was found as $76 \%$ in reduced from and $24 \%$ in oxidized form (instead of 90:10). This could be due to the reduced MDHAR and DHAR activity in tuber tissues (sink) as compared to the photosynthetically active shoot/leaf (source) tissues. MDHAR and DHAR enzyme activity has been reported to be associated with light intensity. One of the environmental signals that activate tuberization in potatoes is light. Delivery of light from the light-receiving organ, the leaf, to an underground organ growing in the dark, the stolon, leads to the formation of potato tuber [27] [36]. However, the underground tubers are exposed to darkness while the photosynthetically active leaf tissues are exposed to the light. This reason, in addition to the reduced DHAR activity in the dark, justify for a reduced DHAR activity in tuber tissues than shoot, and thus reduced amounts of reduced ascorbate in tubers compared to the shoot in this study.

\subsection{Loses of Bioactive Compounds during Potato Processing}

When different processing steps were compared, significant losses of total phenolics, anthocyanins and total antioxidant capacity took place during the peeling $(18 \%-23 \%)$ and blanching processes $(35 \%-60 \%)$. With further cooking/reconstitution, additional losses ranged between $7 \%-12 \%$ with no prominent genotypes differences. Together, $65 \%$ to $90 \%$ of these bioactive compounds were lost during processing. The levels of anothocyanins were found to be affected more in the processing compared to total phenolics and antioxidant capacity. Cultivars with greater initial levels of phenolics (coloured genotypes) lost about 65\% and genotypes those had less phenolics to start with (unpigminted genotypes), lost about $50 \%$ to blanching. 
Significant amounts of bioactive compounds in potato peels also have been reported by others. Ji et al. [37] reported purple and red pigmented potato clones contained higher levels of phenolics and anthocyanins, and had higher antioxidant capacity in both peel and tuber than observed in yellow or unpigmented clones. Samarin et al. [38] also reported significant amounts of phenolic compounds in potato peels, adequate for commercial extraction. Lewis et al. [15] found that purple- and red-skinned tubers contained twice the concentration of phenolic acids as white-skinned tubers. Genotype differences in peeling losses of bioactive compounds were prominent in our study with maximum losses from POROIPG22-1 (phenolics 28\%, anthocyanins $25 \%$ and antioxidant capacity $32 \%$; Table 1 ). This was due to the smaller tuber size ( $98 \mathrm{~g} /$ tuber) of this genotype (Table 1). Though all tubers were peeled with a standard kitchen peeler at a similar depth ( $1-2 \mathrm{~mm})$, as the tubers were of different size, smaller tubers had more tissue removed with the peel compared to the rest of the tuber tissues.

In general, cooking leads to reductions in bioactive compounds and antioxidant capacity for most vegetables (however varies with the methods of cooking) as has been seen in our study. Other studies also have shown that different cooking treatments reduce various phenolic compounds in potatoes [19] [20]. Lachman et al. [39] reported that cooking treatments (boiling, baking and microwaving) reduced ascorbic and chlorogenic acid contents, total glycoalkaloids, a-chaconine and a-solanine with the exception of total anthocyanins.

Significant loss of total phenolics, anthocyanins and antioxidant capacity during blanching of the current study can be attributed to peeling, the browning phenomenon during cut, leaching, levels of temperature and duration and $\mathrm{pH}$ during blanching, selective decomposition, and/or inter-conversion of the compounds [6] [13]. Peeling and slicing of tuber cause browning and expose greater pulp surface to hot water [17] which may facilitate greater leaching of bioactive compounds in water bath during blanching. Perla et al. [19] reported selective leaching of polyphenols from tubers is one of the factors responsible for the decline of polyphenols, flavonoids and flavonols during boiling. They determined that on average, boiling, microwaving and baking reduced total phenolics to $54 \%, 46.5 \%$ and $46 \%$, respectively. Chlorogenic acid, one of the main polyphenols in potatoes, was completely destroyed during baking at $212^{\circ} \mathrm{C}$ in an oven for $45 \mathrm{~min}$, reduced to $35 \%$ and $55 \%$ respectively after boiling for $30 \mathrm{~min}$ in water, or microwaving at $218^{\circ} \mathrm{C}$ for $30 \mathrm{~min}$ and was not detected in commercially processed potato products [20]. Besides altering quantities of polyphenols, food processing that involves heating has been shown to alter flavonols and these alterations directly affected the antioxidant status of plant tissues [16]. Stability of anthocyanins and phenolics are strongly dependant on the $\mathrm{pH}$ value in water media and also the temperature [17]. This and hydrophyllic property of anthocyanin [5] probably justify the maximum loses of anthocyanins during blanching in our study.

Different from literature data that indicate unmodified or an increased amounts of phenolics, anthocyanins and antioxidant capacity after cooking [8] [17], in our study the contents of these bioactive compounds drastically decreased during processing/ cooking. This disagreement may be related to the fact that in those studies the cooking conditions were similar to household cooking and did not involve blanching step as in 
the commercial processing conditions. In some studies, the tubers were not peeled; also either the levels of cooking temperature was low, the cooking duration was less compared to commercial processing, or there was a combination of these two. Indeed, physical and/or chemical changes during processing may differ depending upon the methods used to process potatoes.

\section{Conclusion}

Taken together, these findings suggest that the pigmented potatoes had greater amounts of phenolics, anthocyanins and antioxidant capacity compared to unpigmented genotypes. Total ascorbate contents were not associated to tuber flesh colour. However, the bioactive compounds and antioxidant capacity were significantly reduced by peeling and significantly more blanching, without prominent differences among genotypes. This study suggests that blanching treatments would be one of the most challenging areas to focus on to minimize the adverse effects of processing and to obtain processed/reconstituted products that keep more of their original characteristics including novel bioactive compounds. Peeling process also needs some attention. This work is the first of its kind that focused on the cultivars that the industry recommended, and the processing methods used at the industrial settings. The results are impotent to guide the potato processing industry for their product development and revision of their processing methods.

\section{Acknowledgements}

The research was supported by New Brunswick Enabling Agricultural Research and Innovation (EARI) of Growing Forward Program, McCain Foods Ltd., Canada and Agriculture and Agri-Food Canada (AAFC). The authors also would like to thank Michele Elliot for technical assistance.

\section{References}

[1] Dehghan, M., Mente, A., Teo, K.K., Gao, P., Sleight, P., Dagenais, G., Avezum, A., Probstfield, J.L., Dans, T. and Yusuf, S. (2012) Relationship between Healthy Diet and Risk of Cardiovascular Disease among Patients on Drug Therapies for Secondary Prevention: A Prospective Cohort Study of 31546 High-Risk Individuals from 40 Countries. Circulation, 126, 2705-2712. https://doi.org/10.1161/CIRCULATIONAHA.112.103234

[2] Sapienza, C. and Issa, J.-P. (2016) Diet Nutrition and Cancer Epigenetics. Annual Review of Nutrition, 36, 665-681. https://doi.org/10.1146/annurev-nutr-121415-112634

[3] FAOSTAT (2012) FAO Statistics Division. http://faostat.fao.org/beta/en/\#home

[4] Helgi Library (2013). http://www.helgilibrary.com/indicators/potato-consumption-per-capita/world

[5] Andre, C.M., Ghislain, M., Bertin, P., Oufir, M., Herrera, M.D.R., Hoffmann, L., Hausman, J., Larondelle, Y. and Evers, D. (2007) Andean Potato Cultivars (Solanum tuberosum L.) as a Source of Antioxidant and Mineral Micronutrients. Journal of Agricultural and Food Chemistry, 55, 366-378. https://doi.org/10.1021/jf062740i

[6] Tian, J., Chen, J., Ye, X. and Chen, S. (2016) Health Benefits of the Potato Affected by Domestic Cooking: A Review. Food Chemistry, 202, 165-175. https://doi.org/10.1016/j.foodchem.2016.01.120 
[7] Lachman, J., Hamouz, K., Sulc, M., Orsak, M., Pivec, V., Hejtmankova, A., Dvorak, P. and Jaroslav, C. (2009) Cultivar Differences of Total Anthocyanins and Anthocyanidins in Red and Purple-Fleshed Potatoes and Their Relation to Antioxidant Activity. Food Chemistry, 114, 836-843. https://doi.org/10.1016/j.foodchem.2008.10.029

[8] Navarre, D.A., Shakya, R., Holden, J. and Kumar, S. (2010) The Effect of Different Cooking Methods on Phenolics and Vitamin C in Developmentally Young Potato Tubers. American Journal of Potato Research, 87, 350-359. https://doi.org/10.1007/s12230-010-9141-8

[9] Navarre, D.A., Pillai, S.S., Shakya, R. and Holden, M.J. (2011) HPLC Profiling of Phenolics in Diverse Potato Genotypes. Food Chemistry, 127, 34-41. https://doi.org/10.1016/j.foodchem.2010.12.080

[10] Pillai S.S., Navarre, D.A. and Bamberg, J. (2013) Analysis of Phenolics, Anthocyanins and Carotenoids in Tubers from Solanum tuberosum Group Phureja, Stenotomum and Andigena. American Journal of Potato Research, 90, 440-450. https://doi.org/10.1007/s12230-013-9318-Z

[11] Ducreux, L., Morris, W.L., Hedley, P.E., Shepherd, T., Davies, H.V., Millam, S. and Taylor, M.A. (2005) Metabolic Engineering of High Carotenoid Potato Tubers Containing Enhanced Levels of $\beta$-Carotene and Lutein. Journal of Experimental Botany, 56, 81-89.

[12] Lukaszewicz, M., Matysiak-Kata, I., Skala, J., Fecka, I., Cisowski, W. and Szopa, J. (2004) Antioxidant Capacity Manipulation in Transgenic Potato Tuber by Changes in Phenolic Compounds Content. Journal of Agricultural and Food Chemistry, 52, 1526-1533. https://doi.org/10.1021/jf034482k

[13] Akyol, H., Riciputi, Y., Capanoglu, E., Caboni, M.F. and Varardo, V. (2016) Phenolic Compounds in the Potato and Its Byproducts: An Overview. International Journal of Molecular Sciences, 17, 835. https://doi.org/10.3390/ijms17060835

[14] Brown, C.R., Wrolstad, R., Durst, R., Yang, C.-P. and Clevidence, B. (2003) Breeding Studies in Potatoes Containing High Concentrations of Anthocyanins. American Journal of Potato Research, 80, 241-250. https://doi.org/10.1007/BF02855360

[15] Lewis, C.E., Walkel, J.R.L., Lancaster, J.E. and Sutton, K.H. (1998) Determination of Anthocyanins, Flavonoids and Phenolic Acids in Potatoes. I: Coloured Cultivars of Solanum tuberosum L. Journal of the Science of Food and Agriculture, 77, 45-57. https://doi.org/10.1002/(SICI)1097-0010(199805)77:1<45::AID-JSFA1>3.0.CO;2-S

[16] Makris, D.P. and Rossiter, J.T. (2001) Domestic Processing of Onion Bulbs (Allium cepa) and Asparagus Spears (Asparagus officinalis): Effect on Flavonol Content and Antioxidant Status. Journal of Agricultural and Food Chemistry, 49, 3216-3222. https://doi.org/10.1021/jf001497z

[17] Mulinacci, N., Ieri, F., Giaccherini, C., Innocenti, M., Andrenelli, L., Canova, G., Saracchi, M. and Casiraghi, M.C. (2008) Effect of Cooking on the Anthocyanins, Phenolic Acids, Glycoalkaloids, and Resistant Starch Content in Two Pigmented Cultivars of Solanum tuberosum L. Journal of Agricultural and Food Chemistry, 56, 11830-11837. https://doi.org/10.1021/if801521e

[18] Brown, C.R. (2005) Antioxidants in Potato. American Journal of Potato Research, 82, 163 172. https://doi.org/10.1007/BF02853654

[19] Perla, V., Holm, D.G. and Jayanty, S.S. (2012) Effects of Cooking Methods on Polyphenols, Pigments and Antioxidant Activity in Potato Tubers. Food Science and Technology, 45, 161-171. https://doi.org/10.1016/j.lwt.2011.08.005

[20] Dao, L. and Friedman, M. (1992) Chlorogenic Acid Content of Fresh and Processed Potatoes Determined by Ultraviolet Spectrophotometry. Journal of Agricultural and Food Chemistry, 40, 2152-2156. https://doi.org/10.1021/jf00023a022

[21] Bartoli, C.G., Yu, J., Gomez, F., Fernandaz, L., McIntosh, L. and Foyer, C.H. (2006) Inter- 
Relationships between Light and Respiration in the Control of Ascorbic Acid Synthesis and Accumulation of in Arabidopsis Thaliana Leaves. Journal of Experimental Botany, 57, 1621-1631. https://doi.org/10.1093/jxb/erl005

[22] Singleton, V.L. and Rossi Jr., J.A. (1965) Colorimetry of Total Phenolics with Phosphomolybdic-Phosphotungstic Acid Reagents. American Journal of Enology and Viticulture, 16, 144-158.

[23] Folin, O. and Coicalteu, V. (1927) On Tyrosine and Trypophane Determinations in Proteins. The Journal of Biological Chemistry, 73, 627-650.

[24] Prior, R.L., Hoang, H., Gu, L., Bacchiocca, M., Howard, L., Hampsch-Woodhill, M., Haung, D., Ou, B. and Jacob, R. (2003) Assays for Hydrophilic and Lipophilic Antioxidant Capacity (Oxygen Radical Absorbance Capacity (ORACFL) of Plasma and Other Biological and Food Samples. Journal of Agricultural and Food Chemistry, 51, 3273-3279. https://doi.org/10.1021/jf0262256

[25] Lee, J., Durst, R.W. and Wrolstad, R.E. (2005) Determination of Total Monomeric Anthocyanin Pigment Content of Fruit Juices, Beverages, Natural Colorants, and Wines by the $\mathrm{pH}$ Differential Method: Collaborative Study. Journal of AOAC International, 88, 1269-1278.

[26] Brown, C.R., Culley, D., Yang, C.-P., Durst, R. and Wrolstad, R. (2005) Variation of Anthocyanin and Carotenoid Contents and Associated Antioxidant Values in Potato Breeding Lines. Journal of the American Society for Horticultural Science, 130, 174-180.

[27] Chun, J., Lee, W., Han, M., Lee, J., Yi, Y., Goo, Y., Lee, S., Bae, S., Cho, K. and Chung, C. (2007) Molecular and Biochemical Characterizations of Dehydroascorbate Reductase from Sesame (Sesamum indicum L.) Hairy Root Cultures. Journal of Agricultural and Food Chemistry, 55, 6067-6073. https://doi.org/10.1021/jf070946t

[28] Faller, A.L.K. and Fialho, E. (2009) The Antioxidant Capacity and Polyphenol Content of Organic and Conventional Retail Vegetables after Domestic Cooking. Food Research International, 42, 210-215. https://doi.org/10.1016/j.foodres.2008.10.009

[29] Mohdaly, A.A.A., Sarhan, M.A., Smetanska, I. and Mahmoud, A. (2010) Antioxidant Properties of Various Solvent Extracts of Potato Peel, Sugar Beet Pulp and Sesame Cake. Journal of the Science of Food and Agriculture, 90, 218-226. https://doi.org/10.1002/jsfa.3796

[30] Howard, L.R., Clark, J.R. and Brownmiller, C. (2003) Antioxidant Capacity and Phenolic Content in Blueberries as Affected by Genotype and Growing Season. Journal of the Science of Food and Agriculture, 83, 1238-1247. https://doi.org/10.1002/jsfa.1532

[31] Pantelidis, G.E., Vasilakakis, M., Manganaris, G.A. and Diamantidis, G. (2007) Antioxidant Capacity, Phenol, Anthocyanin and Ascorbic Acid Contents in Raspberries, Blackberries, Gooseberries and Cornelian Cherries. Food Chemistry, 102, 777-783. https://doi.org/10.1016/j.foodchem.2006.06.021

[32] Prior, R. and Wu, X. (2006) Anthocyanins: Structural Characteristics That Result in Unique Metabolic Patterns and Biological Activities. Free Radical Research, 40, 1014-1028. https://doi.org/10.1080/10715760600758522

[33] Noctor, G. and Foyer, C.H. (1998) Ascorbate and Glutathione: Keeping Active Oxygen under Control. Annual Review of Plant Physiology and Plant Molecular Biology, 49, 249-279. https://doi.org/10.1146/annurev.arplant.49.1.249

[34] Chen, Z. and Gallie, D.R. (2006) Dehydroascorbate Reductase Affects Leaf Growth, Development and Function. Plant Physiology, 142, 775-787. https://doi.org/10.1104/pp.106.085506

[35] Jiang, Y., Huang, C., Wen, L. and Lin, C. (2008) Dehydroascorbate Reductasec DNA from Sweet Potato (Ipomoea batatas (L.) Lam): Expression, Enzyme Properties, and Kinetic Studies. Journal of Agricultural and Food Chemistry, 56, 3623-3627. https://doi.org/10.1021/jf073511e 
[36] Ali, M.B., Hahn, E.J. and Paek, K.Y. (2005) Effects of Temperature on Oxidative Stress Defense Systems, Lipid Peroxidation and Lipoxygenase Activity in Phalaenopsis. Plant Physiology and Biochemistry, 43, 213-223. https://doi.org/10.1016/j.plaphy.2005.01.007

[37] Ji, X., Rivers, L., Zielinski, Z., Xu, M., MacDougall, E., Stephen, J., Zhang, S., Wang, Y., Chapman, R.G., Keddy, P., Robertson, G.S., Kirby, C.W., Embleton, J., Worrall, K., Murphy, A., Koeyer, D.D., Tai, H., Yu, L., Charter, E. and Zhang, J. (2012) Quantitative Analysis of Phenolic Components and Glycoalkaloids from 20 Potato Clones and in Vitro Evaluation of Antioxidant, Cholesterol Uptake, and Neuroprotective Activities. Food Chemistry, 133, 1177-1187. https://doi.org/10.1016/j.foodchem.2011.08.065

[38] Samarin, A.M., Poorazarang, H., Hematyar, N. and Elhamirad, A. (2012) Phenolics in Potato Peels: Extraction and Utilization as Natural Antioxidants. World Applied Sciences Journal, 18, 191-195.

[39] Lachman, J., Hamouz, K., Musilova, J., Hejtmankova, K., Kotikova, Z., Pazderu, K., Domkarova, J., Pivec, V. and Cimr, J. (2013) Effect of Peeling and Three Cooking Methods on the Content of Selected Phytochemicals in Potato Tubers with Various Color of Flesh. Food Chemistry, 138, 1189-1197. https://doi.org/10.1016/j.foodchem.2012.11.114

\section{Submit or recommend next manuscript to SCIRP and we will provide best service for you:}

Accepting pre-submission inquiries through Email, Facebook, LinkedIn, Twitter, etc. A wide selection of journals (inclusive of 9 subjects, more than 200 journals) Providing 24-hour high-quality service User-friendly online submission system Fair and swift peer-review system Efficient typesetting and proofreading procedure Display of the result of downloads and visits, as well as the number of cited articles Maximum dissemination of your research work

Submit your manuscript at: http://papersubmission.scirp.org/ Or contact fns@scirp.org 